\title{
An Analysis of Humorous Devices in Picturebooks:
A Pictorial Article
-Elys Dolan
}

Keywords: humour; pictorial; picture books: children's illustration

The purpose of this pictorial article is to demonstrate types of humour found in picturebooks and how the characteristics of the picturebook are deployed in their execution.

There are a great variety of definitions concerning what a picturebook is, but in the context of this article, Barbara Bader's definition is most applicable. Bader describes the picturebook "[a]s an art form [that] hinges on the interdependence of pictures and words, on the simultaneous display of two facing pages, and on the drama of the turning page" (1).

Demonstrating types of humour found in picturebooks, as opposed to purely analyzing existing instances of such humour, allows the reader the opportunity to experience comedic amusement. Therefore, this article is written and illustrated in the manner of a picturebook, using the conventions of the form, such as characters, setting, and word-image interplay. It is imperative that this article should be read as a picturebook would, with the reader considering both words and pictures together simultaneously and extracting meaning from their experience of the two working together.

To deliver this effect in the most compelling manner, this article is intended to be read in the form of a book, with two facing pages joined by a spine. Due to the need to reproduce this article in the two different formats required by both the print and digital versions of this journal, it has not been possible to display it in that manner. Therefore, one single page in this journal presents two facing pages of the article.

Please continue to turn the pages and wait for your lecturer to arrive. 


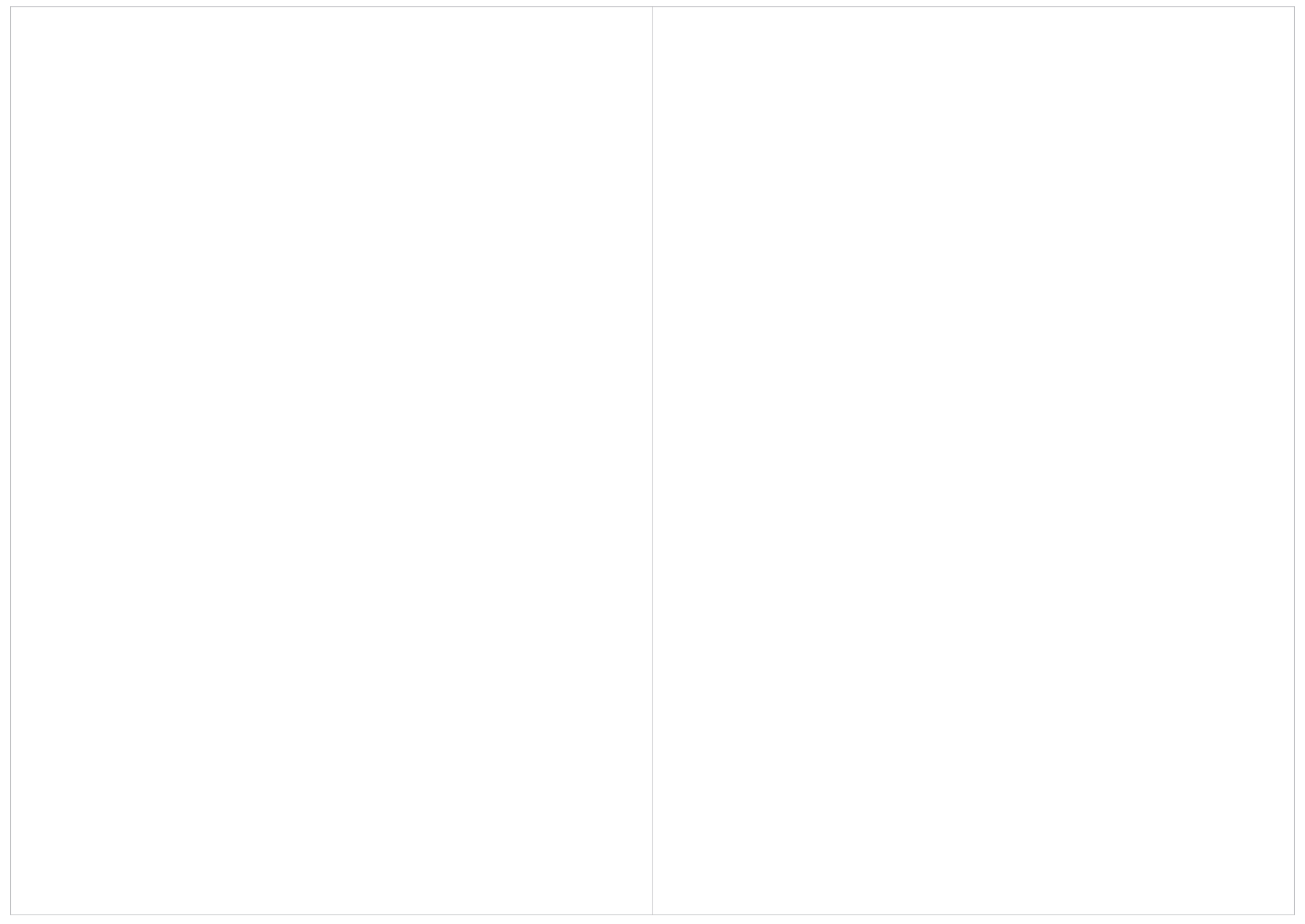




\section{Good day.}

I'm the Professor, and today I shall be lecturing you on the more practical side of humour in picturebooks. I shall demonstrate some of the methods that picturebook makers use to create humorous content.

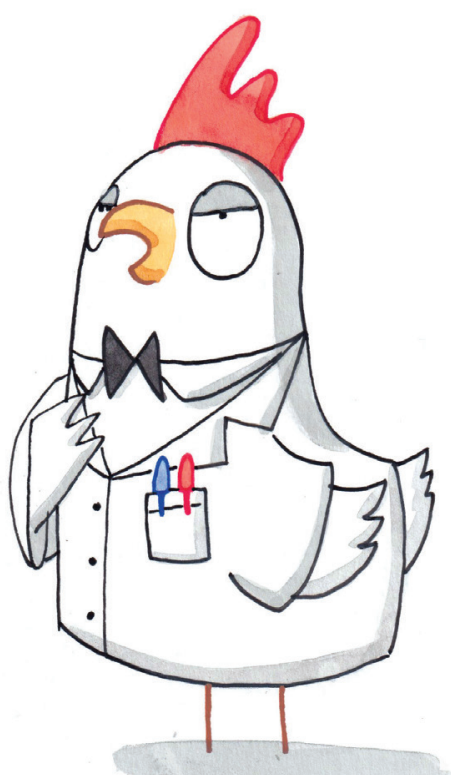


As you can see from my attire, I am a legitimate academic.

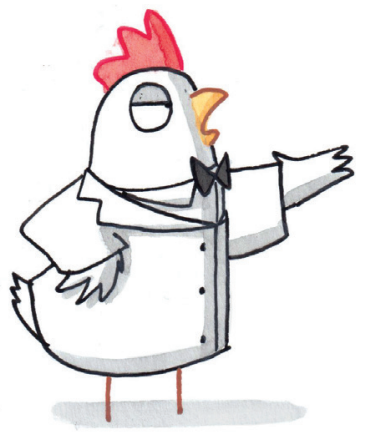

But first, you must fill out this participant consent form.

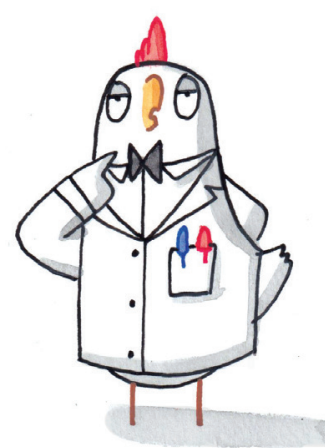

'm going to demonstrate what I believe are the most prevalent types of humour found within icturebooks and analyze the mechanics through thich they are delivered.

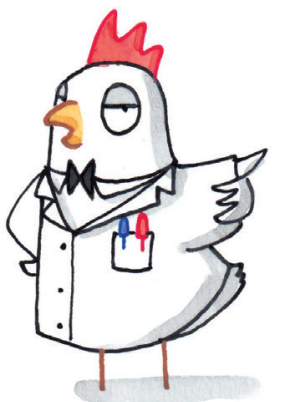

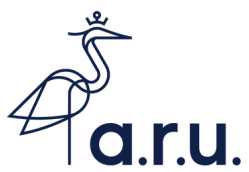

\section{NAME OF PARTICIPANT:}

DATE:

FORM NUMBER:

1. Do you have a sense of humour? $\mathbf{Y} / \mathbf{N}$

2. Do you have any medical conditions? $\mathbf{Y} / \mathbf{N}$

3. Do you have any issues with poo? $\mathbf{Y} / \mathbf{N}$

4 Do you have any criminal convictions? $\mathbf{Y}$ / N

5. Would you like any? $\mathbf{Y} / \mathbf{N}$

6. Do you have a history of monkey bites? $\mathbf{Y} / \mathbf{N}$

7. Are you wearing a bow tie? $\mathbf{Y} / \mathbf{N}$

Data Protection: I agree to the University processing personal data which I have supplied. I agree to the processing of such data for any purposes connected with the Research Project as outlined to me.

Name of participant (print) Signed. Date

PARTICIPANTS ARE FREE TO WITHDRAW AT ANY POINT WITHOUT GIVING A REASON EVEN THOUGH IT WOULD BE QUITE RUDE. 
Now that you have completed the form, please hand it to your Faculty Liaison Officer to the right.

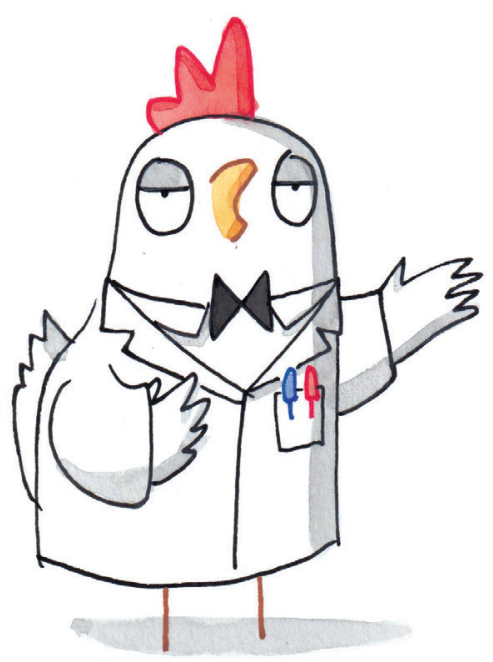

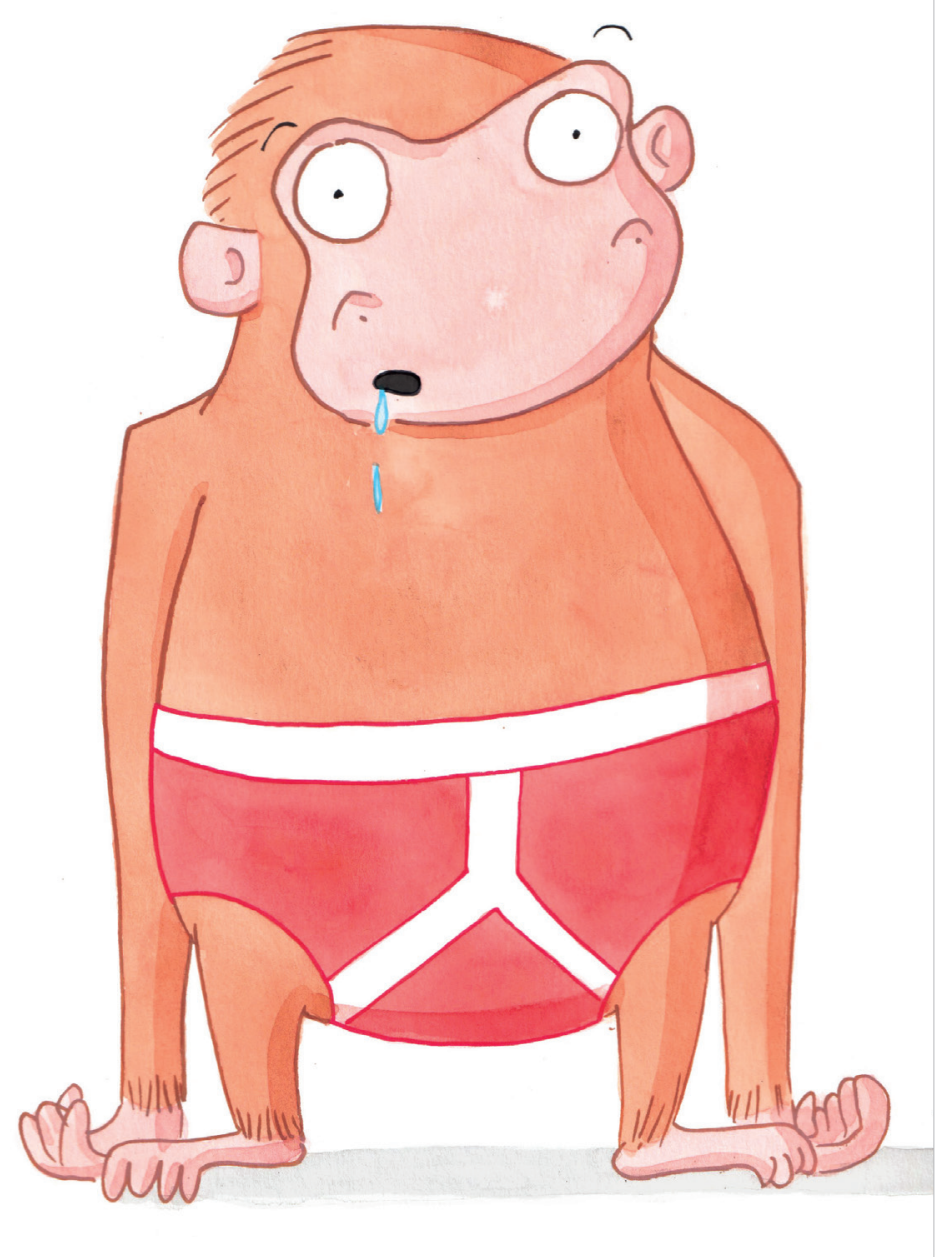


Conveniently, your Faculty Liaison Officer also happens to be my research assistant. Let me introduce you properly. This is Underpants Monkey. He'll be assisting me with some of the demonstrations.

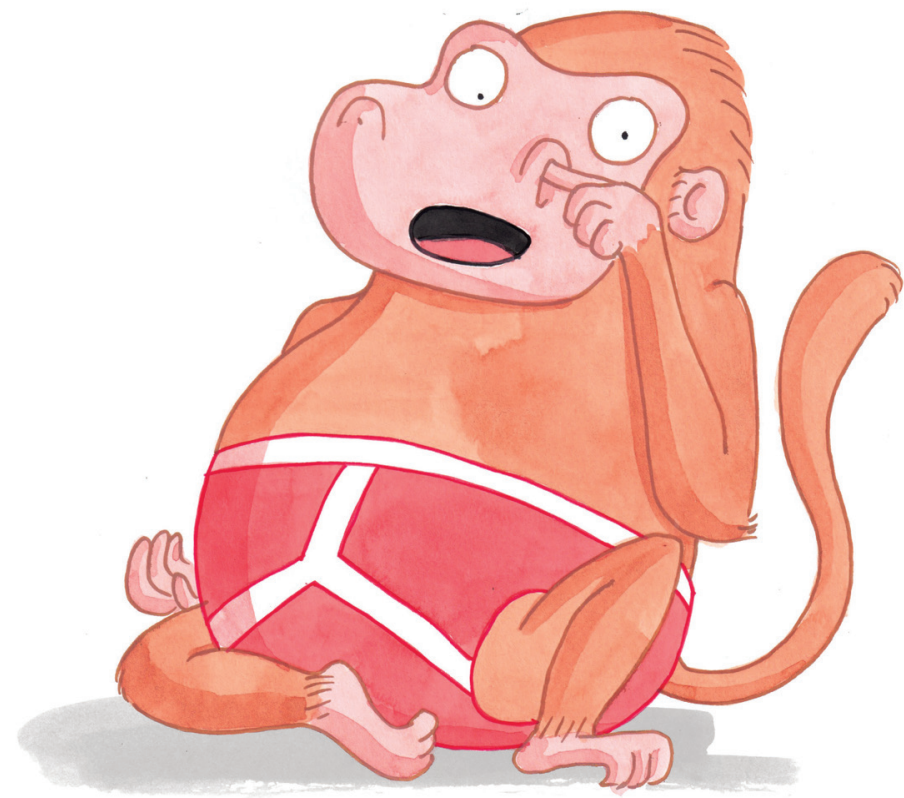

As you know, today I'm going to be explaining humour, or "funny stuff" as we academics call it. The issue is, as E. B. White and Katharine White state, "Humor can be dissected, as a frog can, but the thing dies in the process and the innards are discouraging to any but the purely scientific mind" (16). By analyzing comedy, it is said that you dramatically diminish its humorous effect.

For example, take Underpants Monkey. If I tell you that...

This monkey is funny because he's wearing underpants and underpants are funny because underpants cover bums and bums are funny because bums are rude and rude things are funny...etc.,

it's much less amusing than if you came to this realization independently.

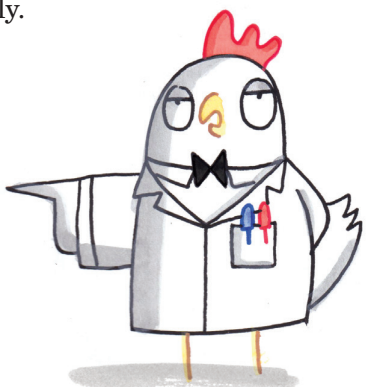

So, if you explain why something is funny or tell people what they should find funny, it automatically becomes unfunny... 
...no matter how hard you try.

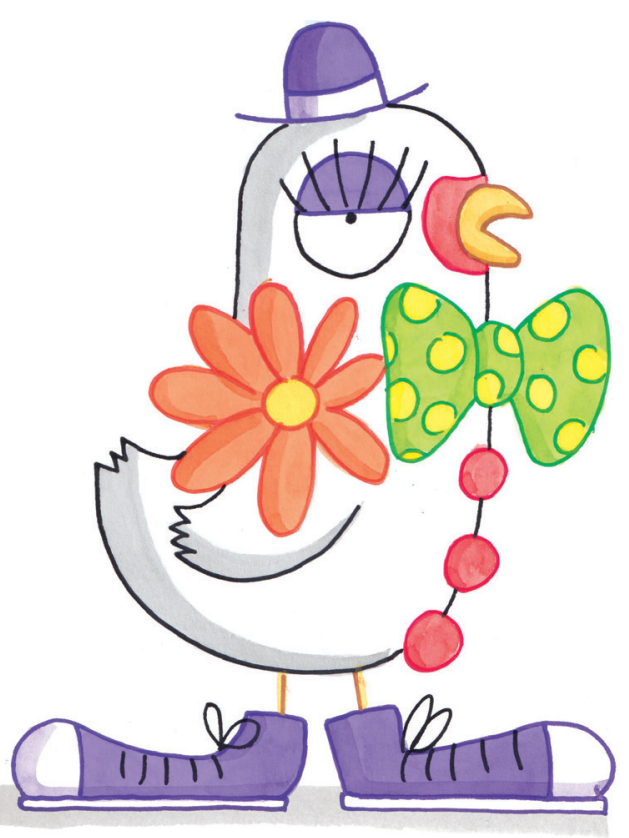

Therefore, we can safely assume that this process is going to ruin some jokes for you. If you want to see these mechanisms used to their full effect, do refer to the recommended reading I shall prescribe. Let us begin. 


\section{Exaggeration}

This can apply to situations and settings, but in picturebooks, exaggeration is often used in characterization. If elements of a character are exaggerated beyond audience expectations (Brown 192), it often creates a humorous effect. Let me show you:

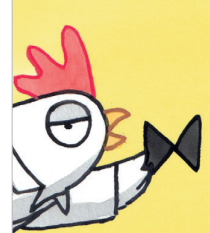

Hold my bow tie. This could get messy.

Or excessively round.

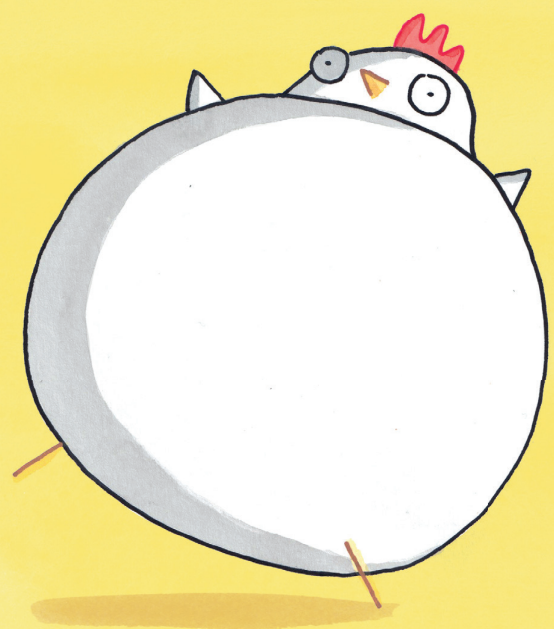

I could be implausibly tall.

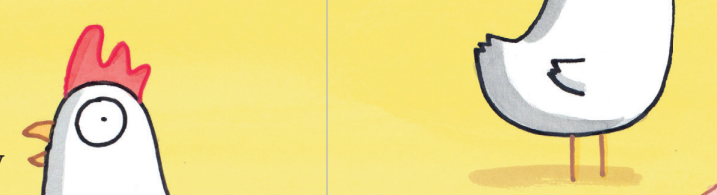

Or have absurd hair that no respectable academic would consider acceptable.

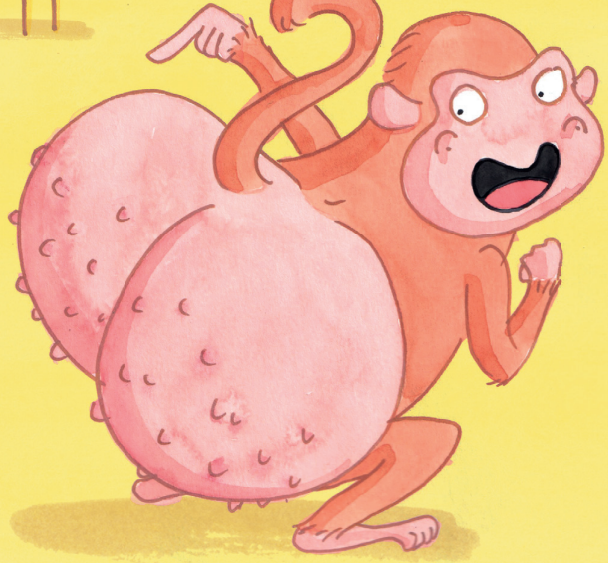

Thank you for your input, Underpants Monkey. That is applicable but perhaps not in keeping with the tone of this lecture. Now, let us examine a different form of exaggeration through characterization. 
It's not just physical characteristics you can exaggerate for humorous effect, you can also exaggerate reactions or emotions. Underpants Monkey will now demonstrate some of his exaggerated feelings:

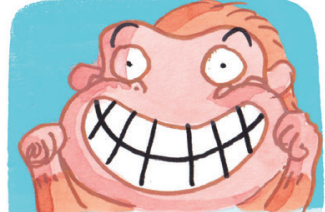

Really happy.

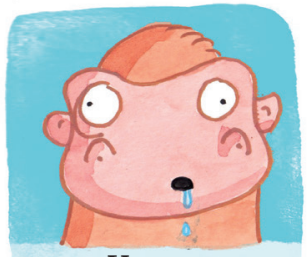

Vacant.

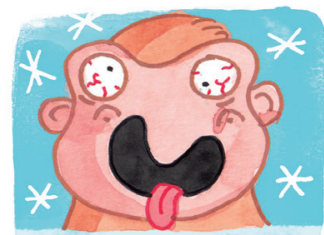

Intoxicated.

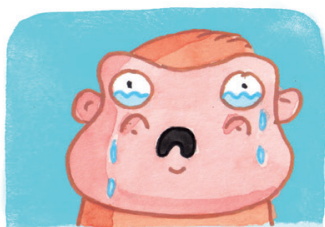

So sad.

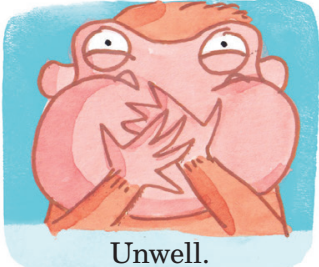

Unwell.

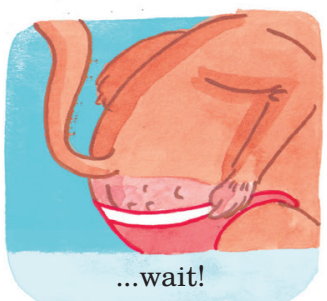

\section{MONKEY! DON'T YOU} DARE DO THAT AGAIN!

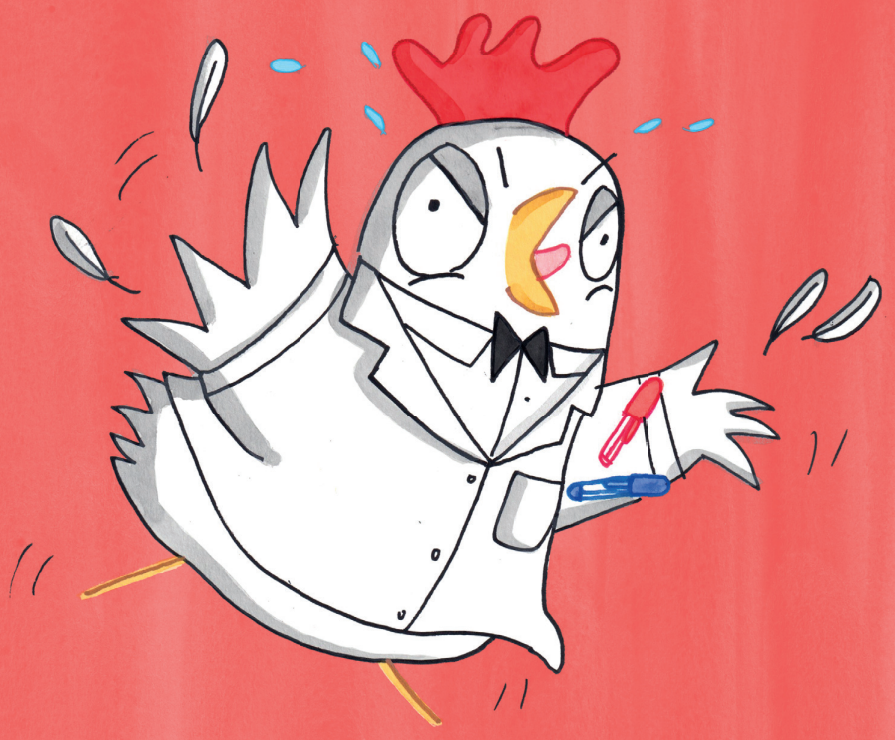

It is evident that emotional exaggeration can be applied to characters that embody self-possession and control. This break from and contrast to their typical behaviour intensifies the humorous effect. 


\section{Slapstick}

We can define slapstick as a kind of physical comedy that relies upon violence, physical punishment, and exaggerated misfortunes that are not truly life-threatening (Brown 194; Weitz 57). For example...
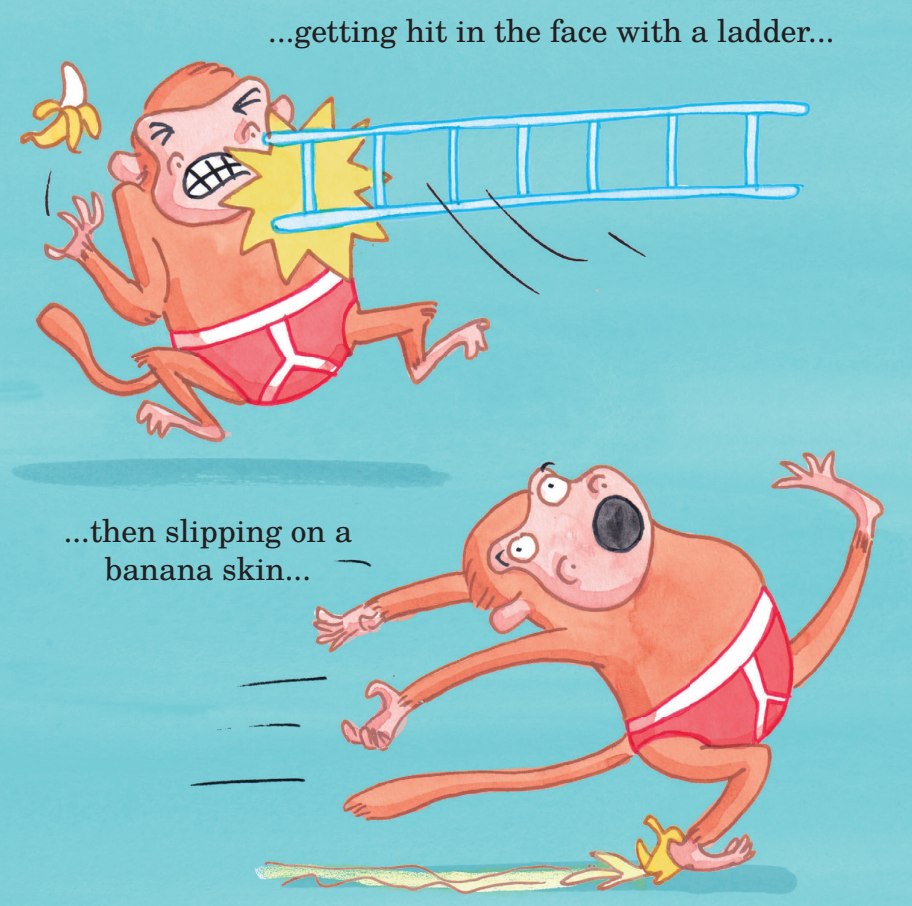

...and then instantly getting kicked in the gonadal region...

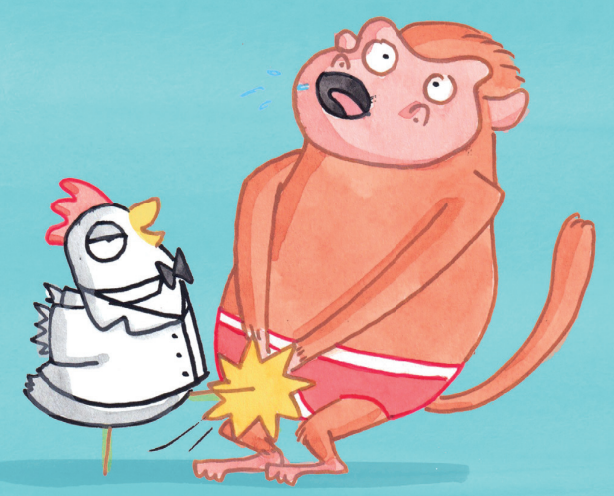

...which causes your underpants to fall down...

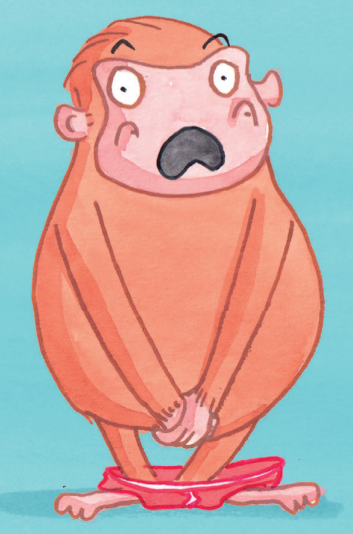

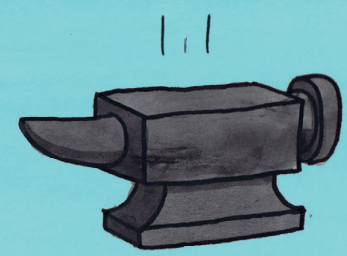

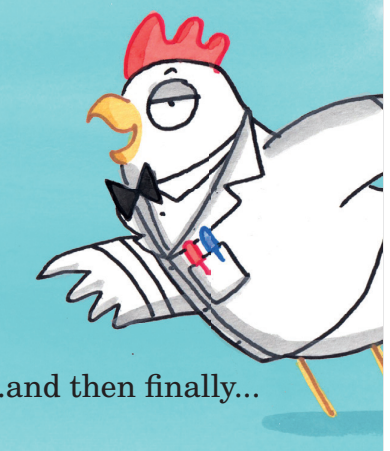




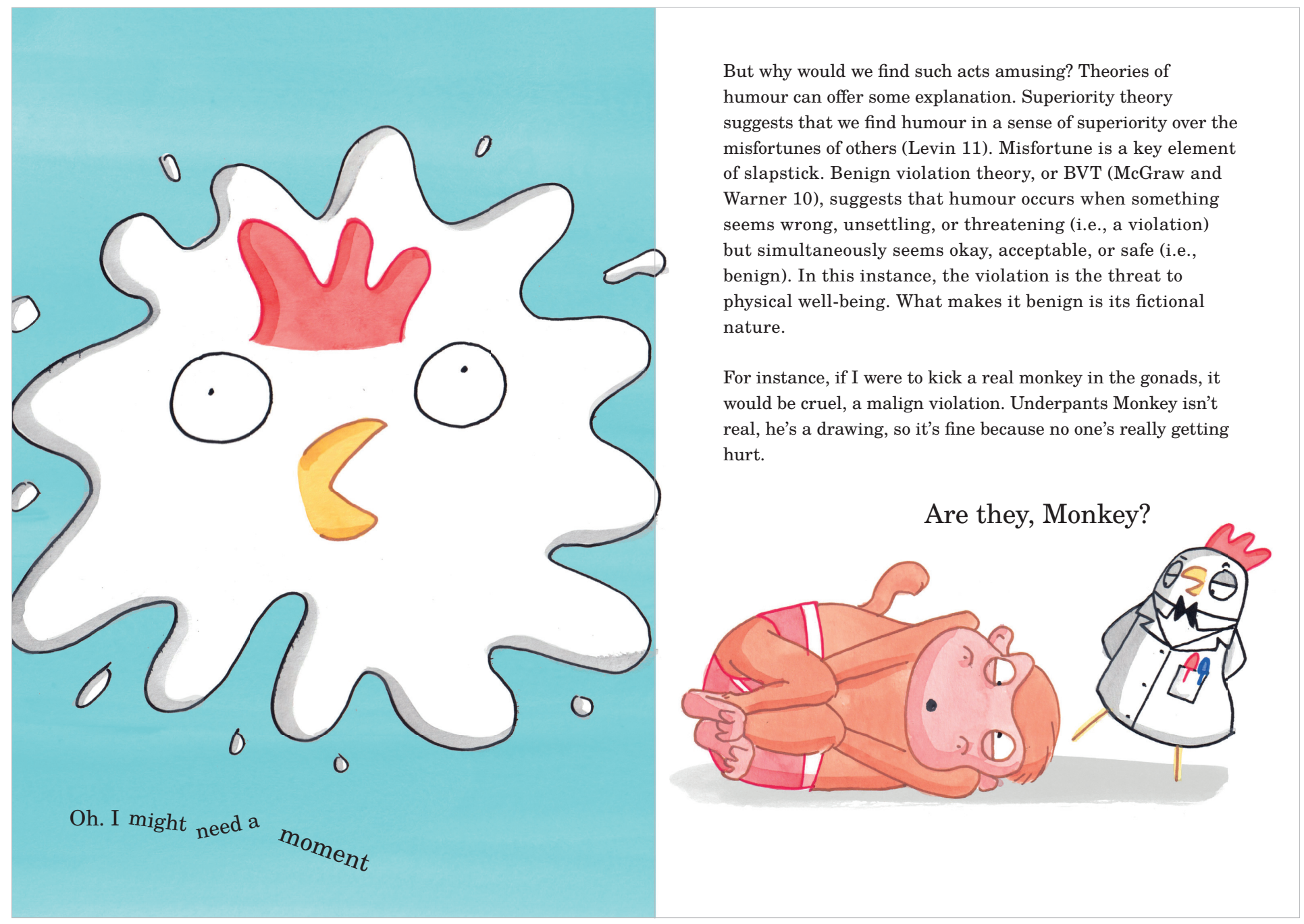


It could be said that such humour is highly dependent on the nature of the character. If the subject possesses a certain amount of emotional distance from the reader, it appears to help determine the effectiveness of the joke.

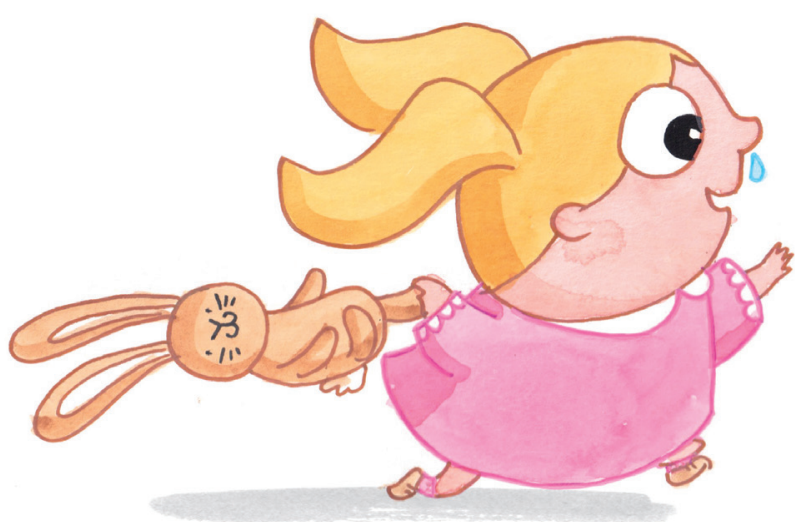

For instance, if I were to kick this adorable child in the face, it would not be as funny. This could be because human characters bear more similarity to the reader, so seem more real or "mimetic" (Nikolajeva 8). Therefore, the violation becomes malign as we empathize more with the character's distress and the humorous effect is diminished.

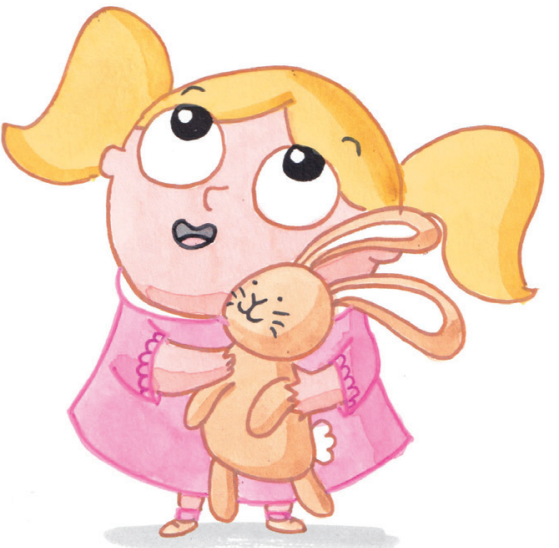

So, clearly, it would be inappropriate to kick this child. 


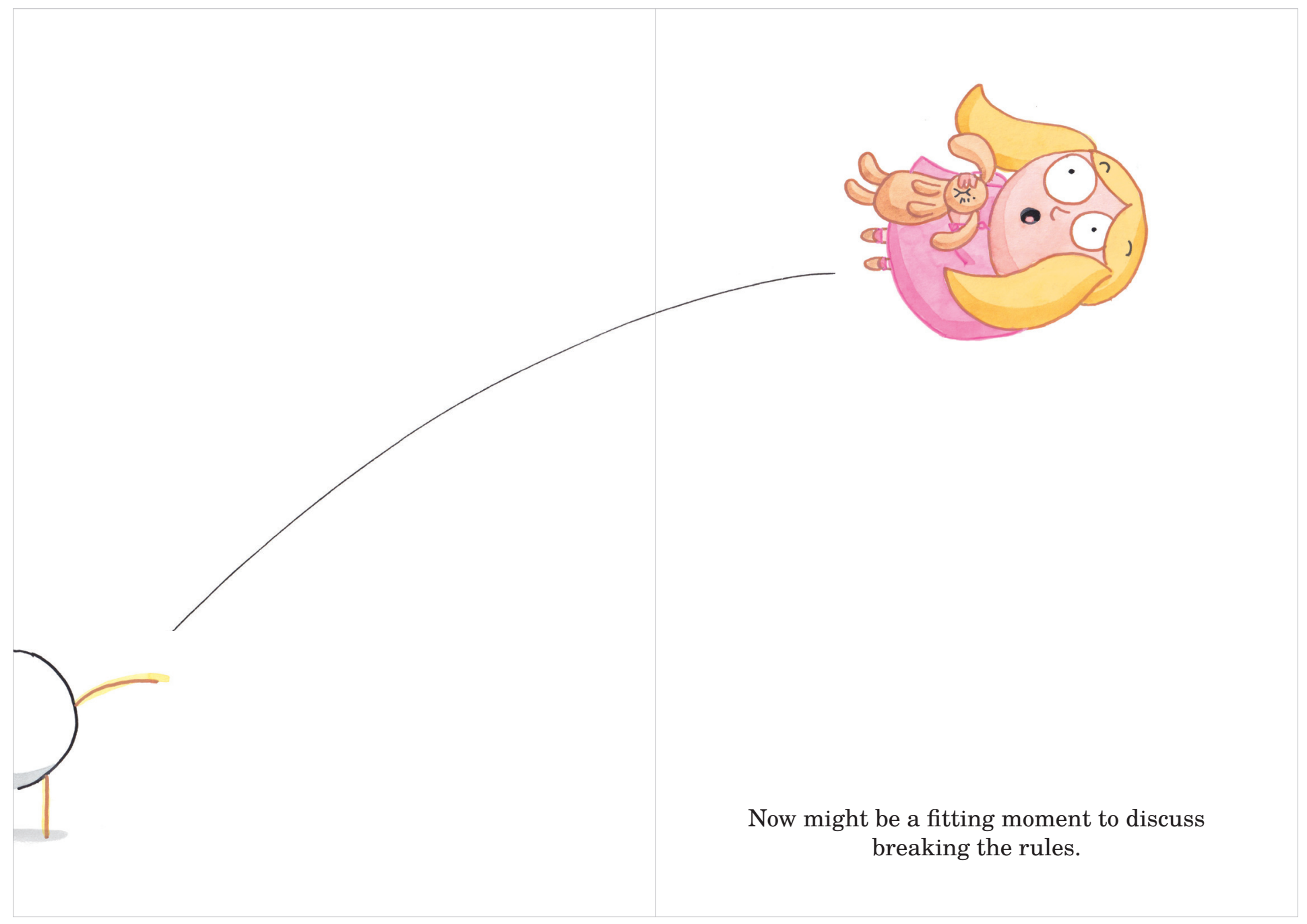




\section{Rule-Breaking}

Yes, that's a great idea! Let me demonstrate. I could do something like shout

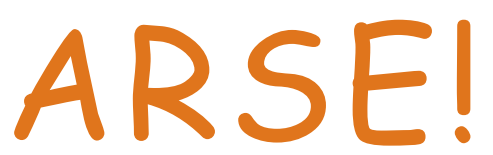

in the middle of an academic journal!

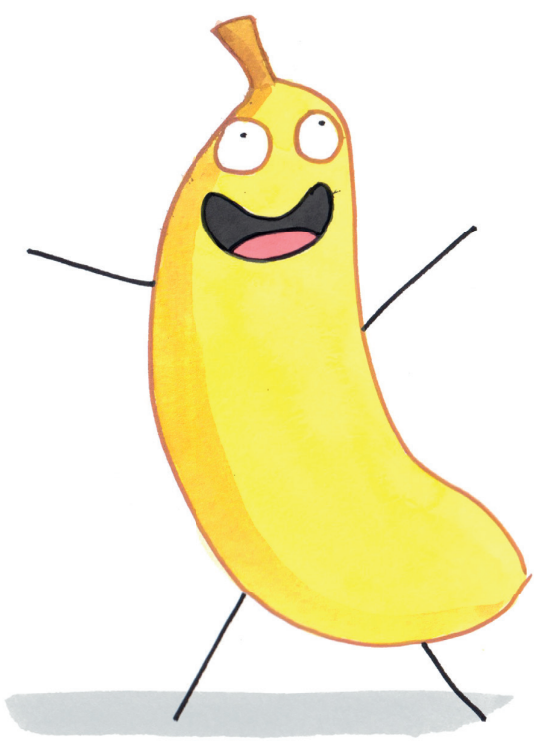

What right have you got to talk about humour? What's your publication history?

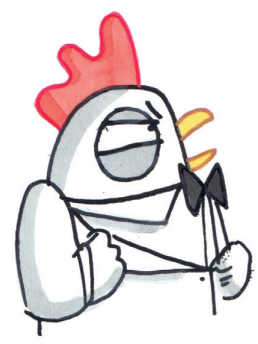

But... are you aware of the preconceptions associated with Comic Sans?

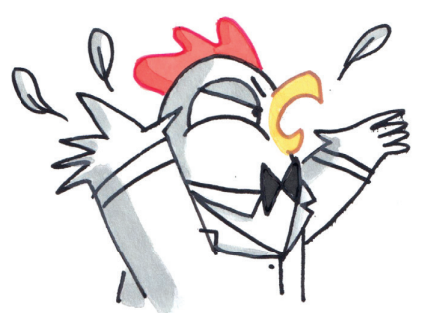

Can you provide a compelling theory as to why any of this is humorous?
I'm Banana! Your monkey stepped on me earlier. I'm well-known graduate student, and you can tell I'm funloving and hilarious because I speak in Comic Sans.

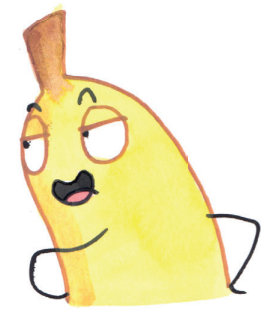

I'm a maverick who doesn't play by the rules. I defy conventions and laugh at authority, so I'm borderline

$$
\text { unemployable. }
$$
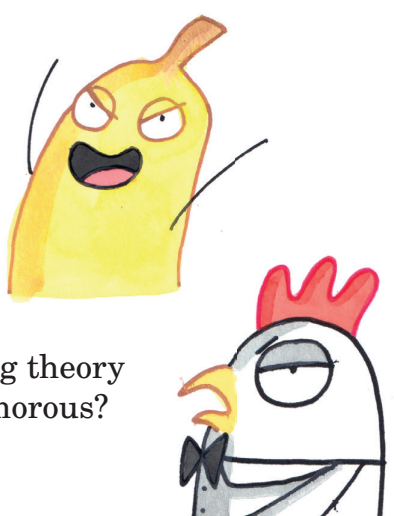


\section{Relief Theory \\ Obviously.
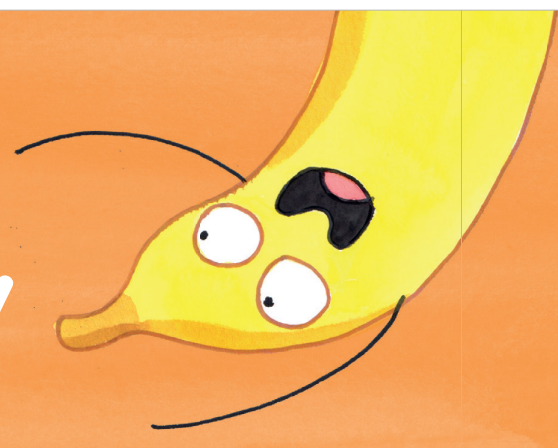

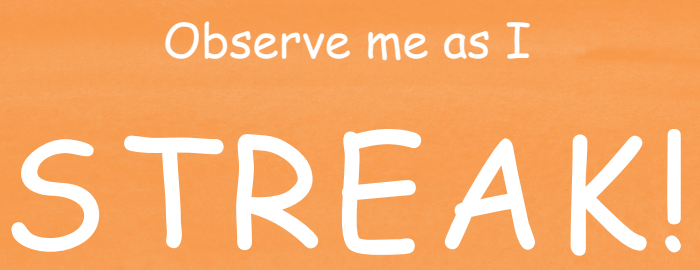

Relief theory suggests that we find something humorous when a convention is violated, causing a release of tension or restraint (Monro 353). So, when we break rules, which are social conventions in themselves, we find it amusing.

Equally, the humorous nature of the violation of social conventions seen here could be explained by BVT. It is benign because there are no real-life consequences to my actions. This is an article and the situation is fictional. So, there's no harm in breaking a few more rules..
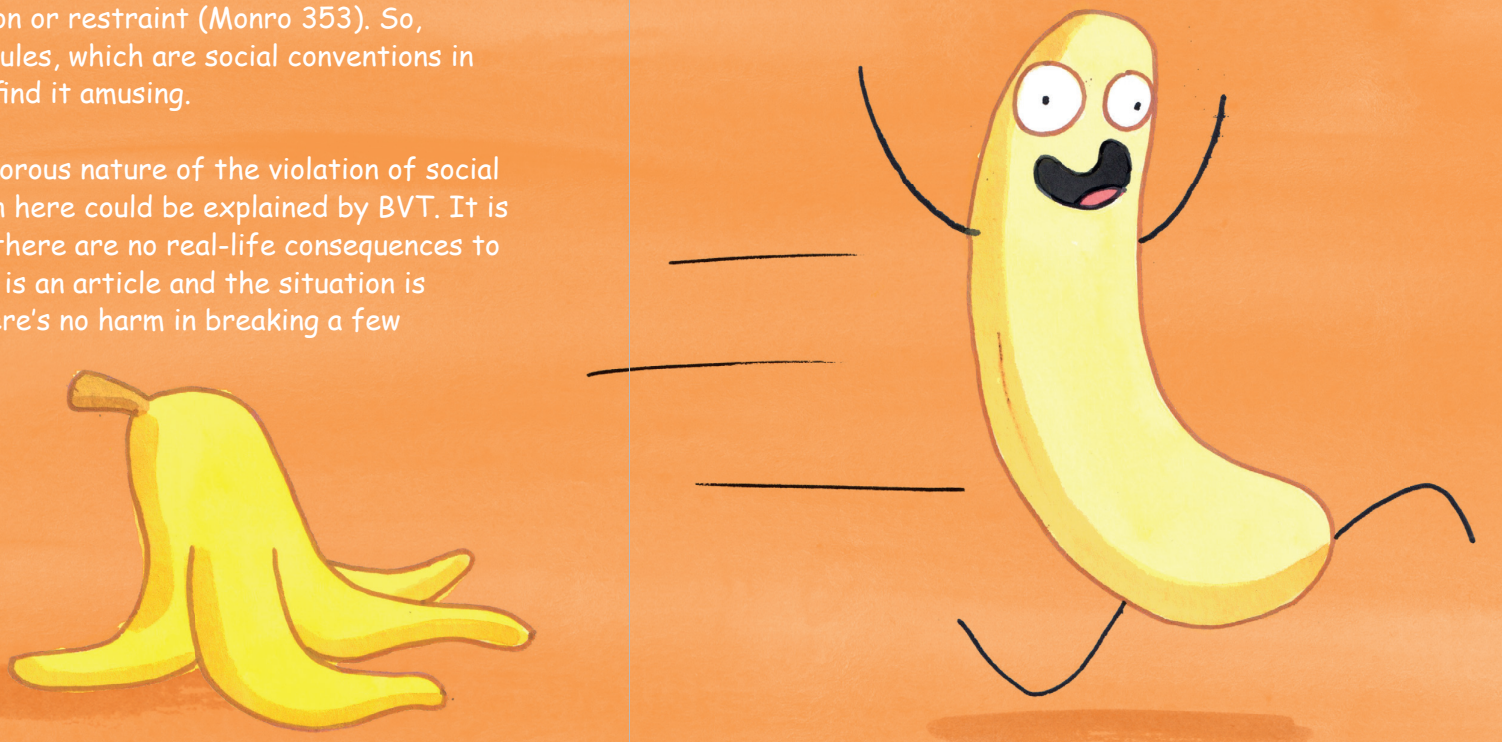
Banana, it is time for you to desist because you are undermining the structure of my lecture. In addition, I cannot stand your font choice. I shall take over.

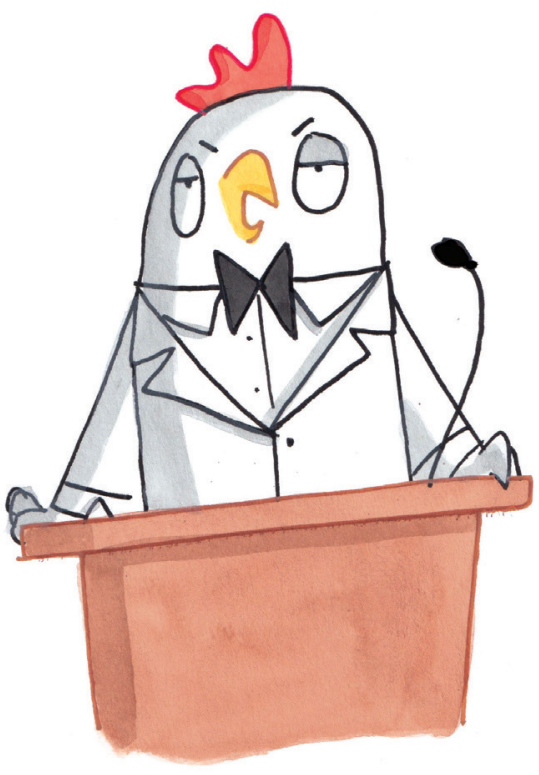

Rule-breaking for humorous effect in picturebooks is common. This can take the form of breaking social conventions and taboos or the violation of the physical conventions of the picturebook itself.

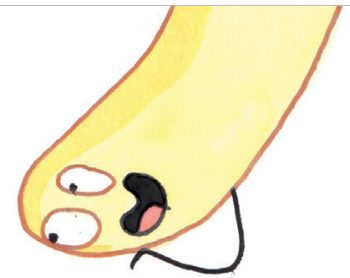

Do you know what makes rulebreaking even funnier?

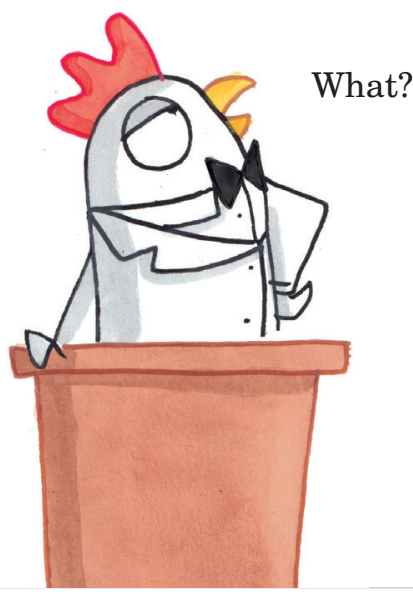




\section{WHEN IT HAPPENS TO AUTHORITY FIGURES!}

This situation could be seen as even funnier because it violates not only the social convention of not throwing eggs at people but also the convention that suggests we must show respect to authority figures such as teachers, parents, political leaders, and, of course, professors.

In addition, this could also relate to superiority theory. Such an offence to the dignity of an authority figure, the very sort of person who is often our superior, can provide the reader with a novel instance of feeling superior to them.
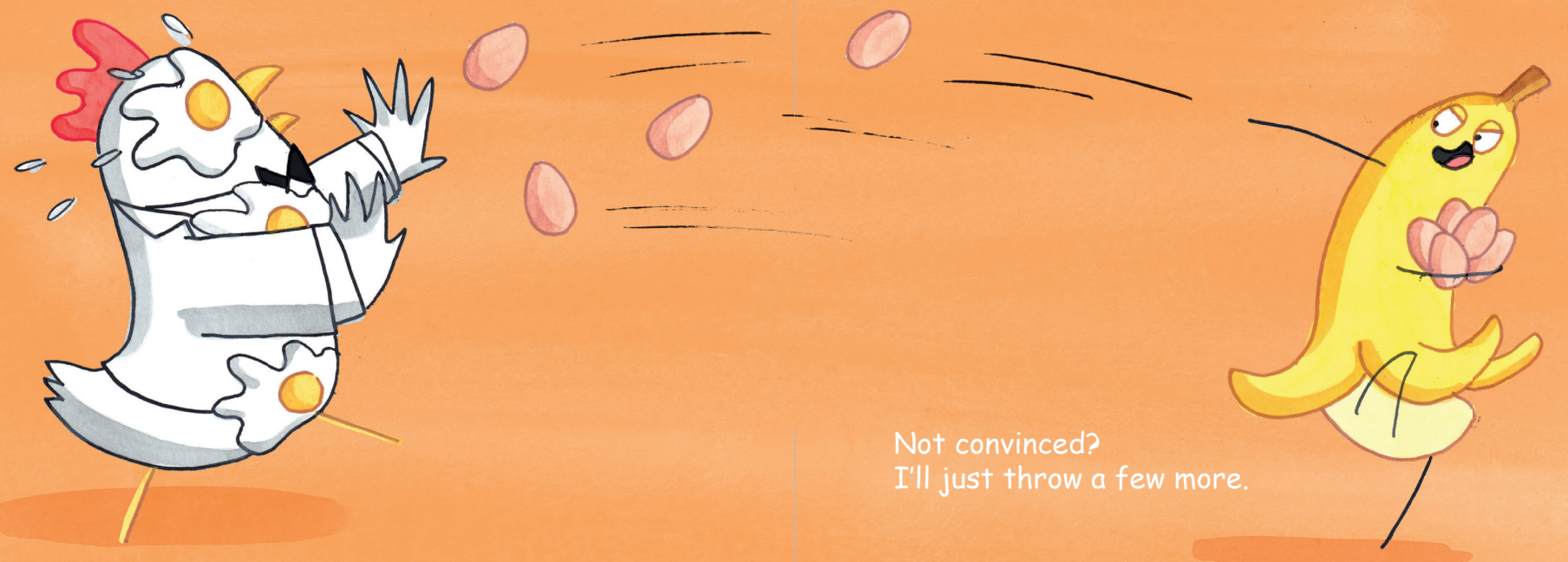
Underpants Monkey? Will you kindly remove this disruptive student from my classroom?

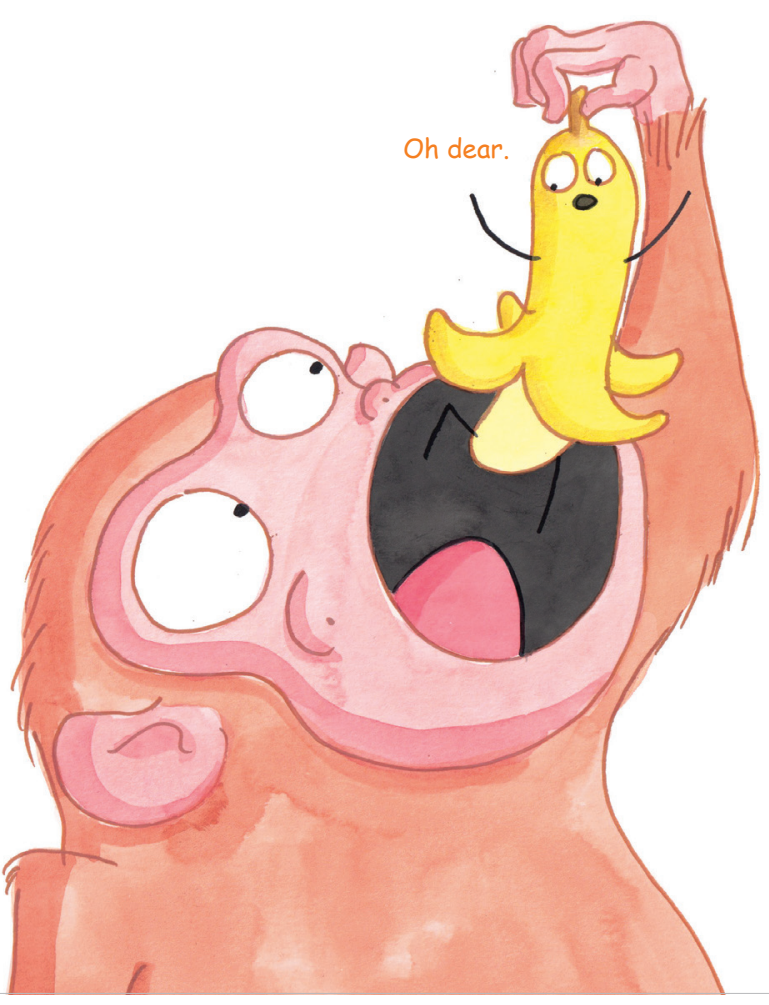

Thank you. I shall report him to his Head of Department when he comes out the other end. Though, after further consideration, I will concede that eating graduate students is a form of rule-breaking in itself, making this an effective demonstration.

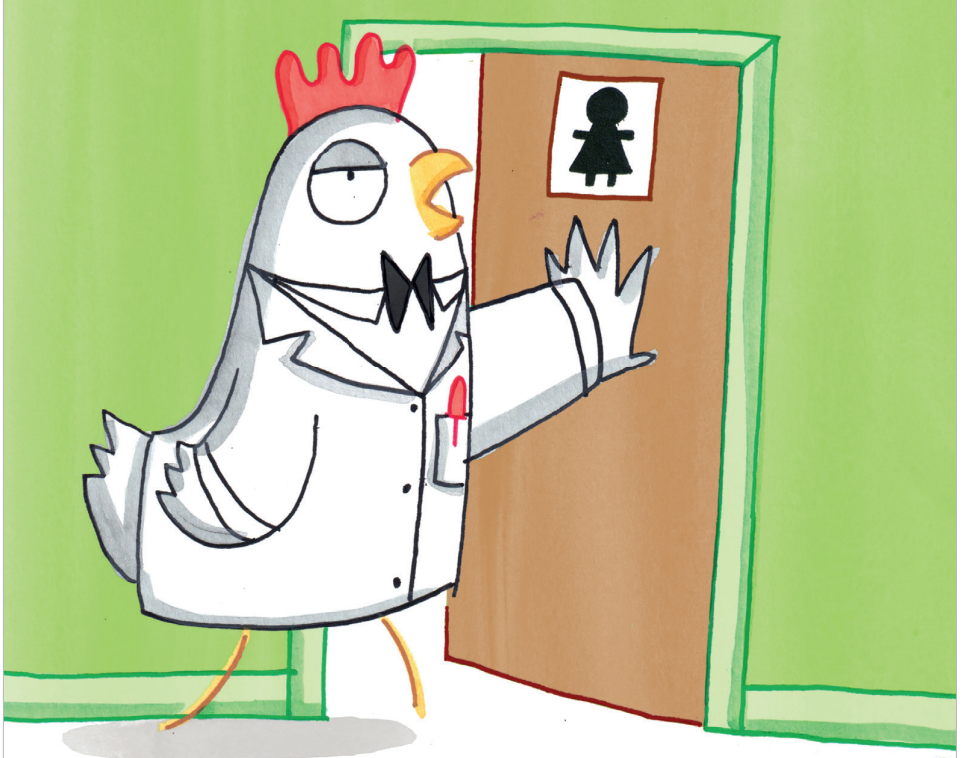

Speaking of the other end, we should probably address toilet humour. Come with me. 
Oh excellent. That must mean it's time for my bit.
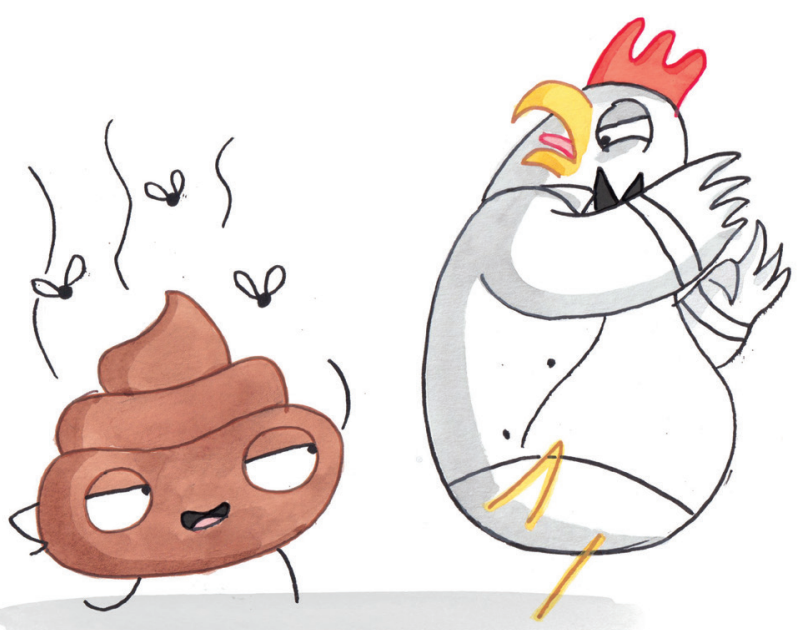

$\mathrm{WHO}_{\text {are you? }}$
Hi, I'm Poo. I'm a new faculty member.

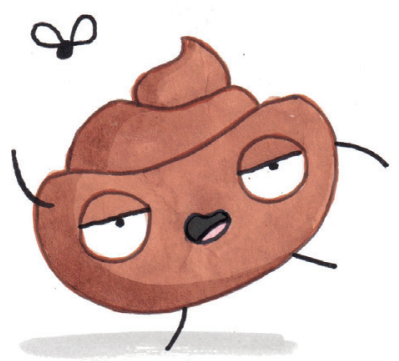

I'm one of those modern lecturers who everyone likes.

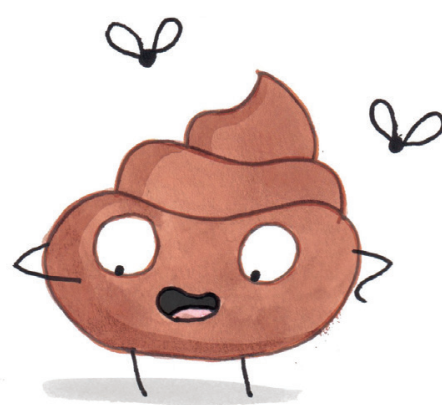

a tie.

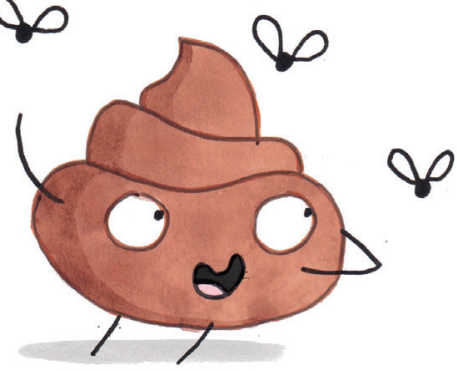

I don't even wear

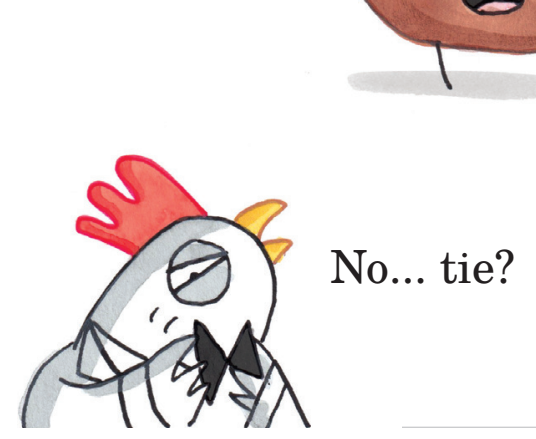




\section{Toilet Humour}

You'll find I'm quite the expert in my field. Maurice Saxby suggests that "physical functions of the body can beextremely funny" (317), for a young audience, so we simply must talk about toilet, or scatological, humour. We could define it as humour that relies upon the use of bodily functions, effluents, and taboo body parts. Examples

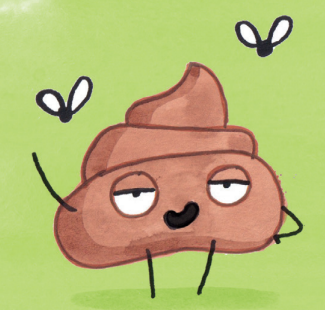

Poo, my good self. Also, my cousin wee.
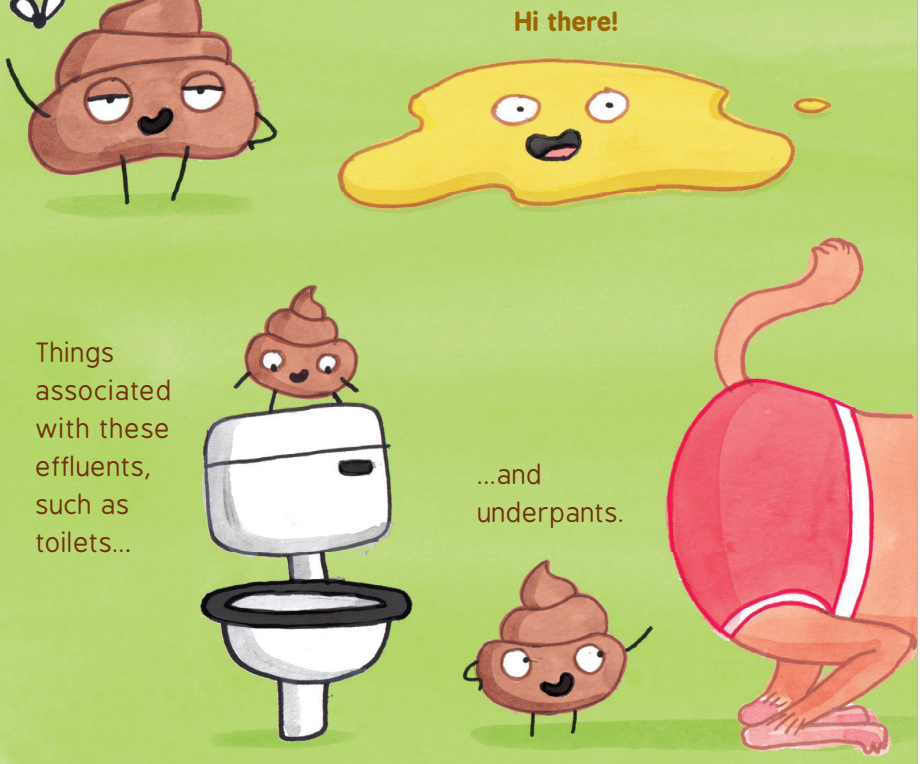

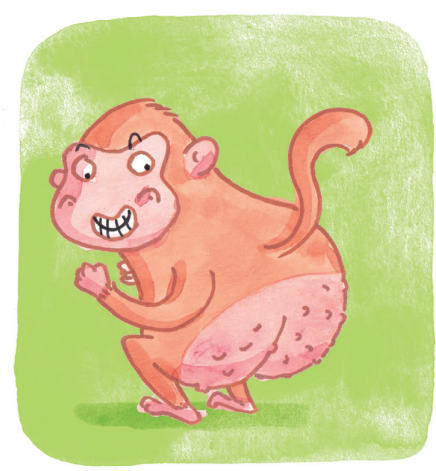

Then there's taboo body parts like bums. You really have a talent, Underpants Monkey!

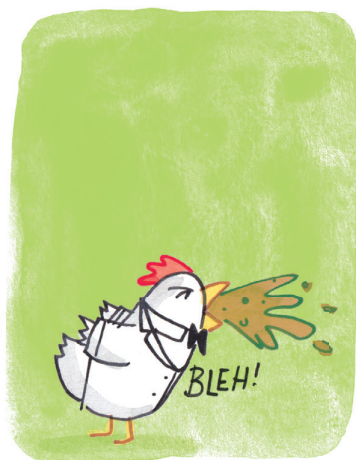

Oh yes, vomit! Excellent output, Professor.

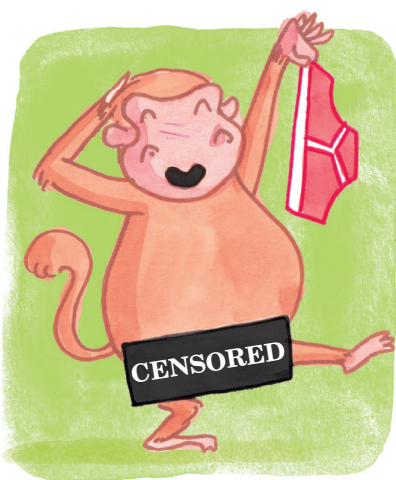

Genitalia would come under this but may not be seen as age or culturally appropriate for a young readership. 
I struggle to see why this is humorous.

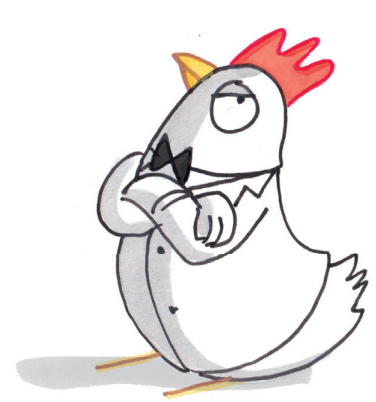

Oh, but it is!

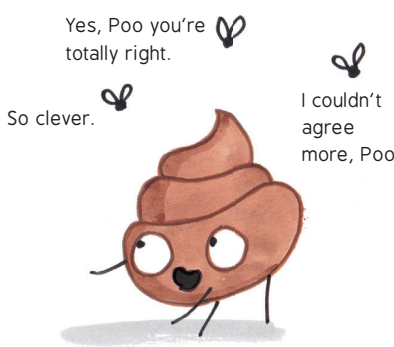

Many picturebooks utilize toilet humour, with varying degrees of subtlety. This perhaps relates to what Michael Rosen suggests, that "at the heart of a good deal of comedy is anxiety." We experience anxiety around wee and similar bodily functions, concerning the shame around putting them in the right, or wrong, places. He suggests that taking these things out of the context of shame and using them for different applications, in this case for the serious business of comedy, relieves that anxiety. This ties in closely with relief theory.

It also fits with BVT. Displaying taboo bodily functions violates a social convention, but it does not cause serious harm. Though I admit Underpants Monkey's gonadal region is perhaps a malign violation, which suggests that toilet humour can tread a fine line between malign and benign violation.
I find it funny.

Where did you come from?

That monkey just used the

toilet on the previous page.

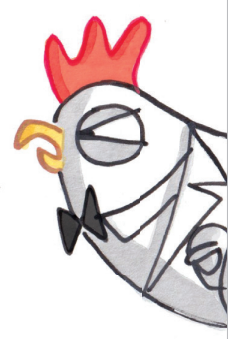

This excess of scatological humour is objectionable and, more importantly, not consistent with my lesson plan. Is a junior lecturer such as yourself even aware of the origins of poo?

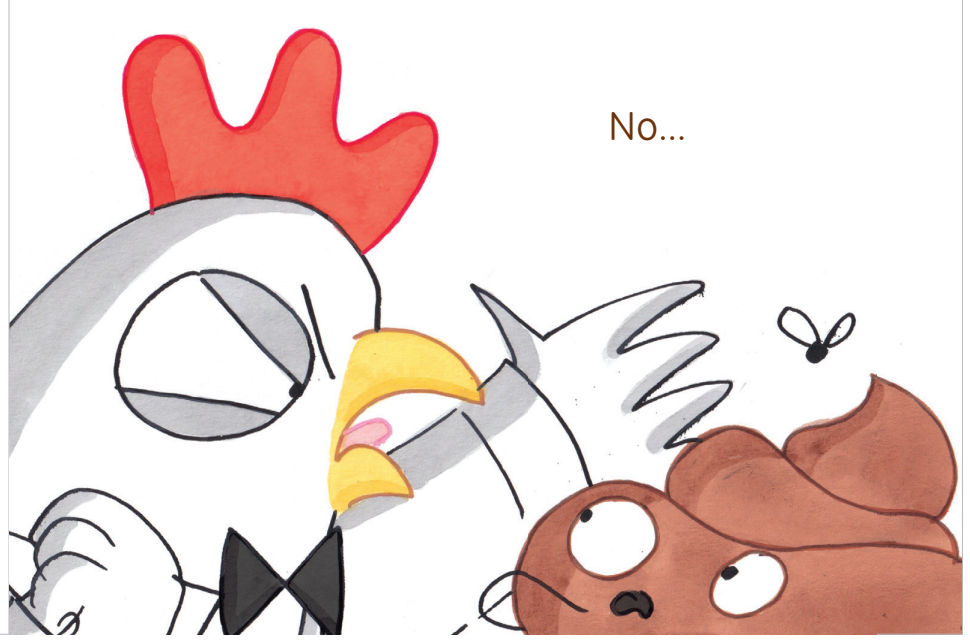


Allow me to enlighten you.

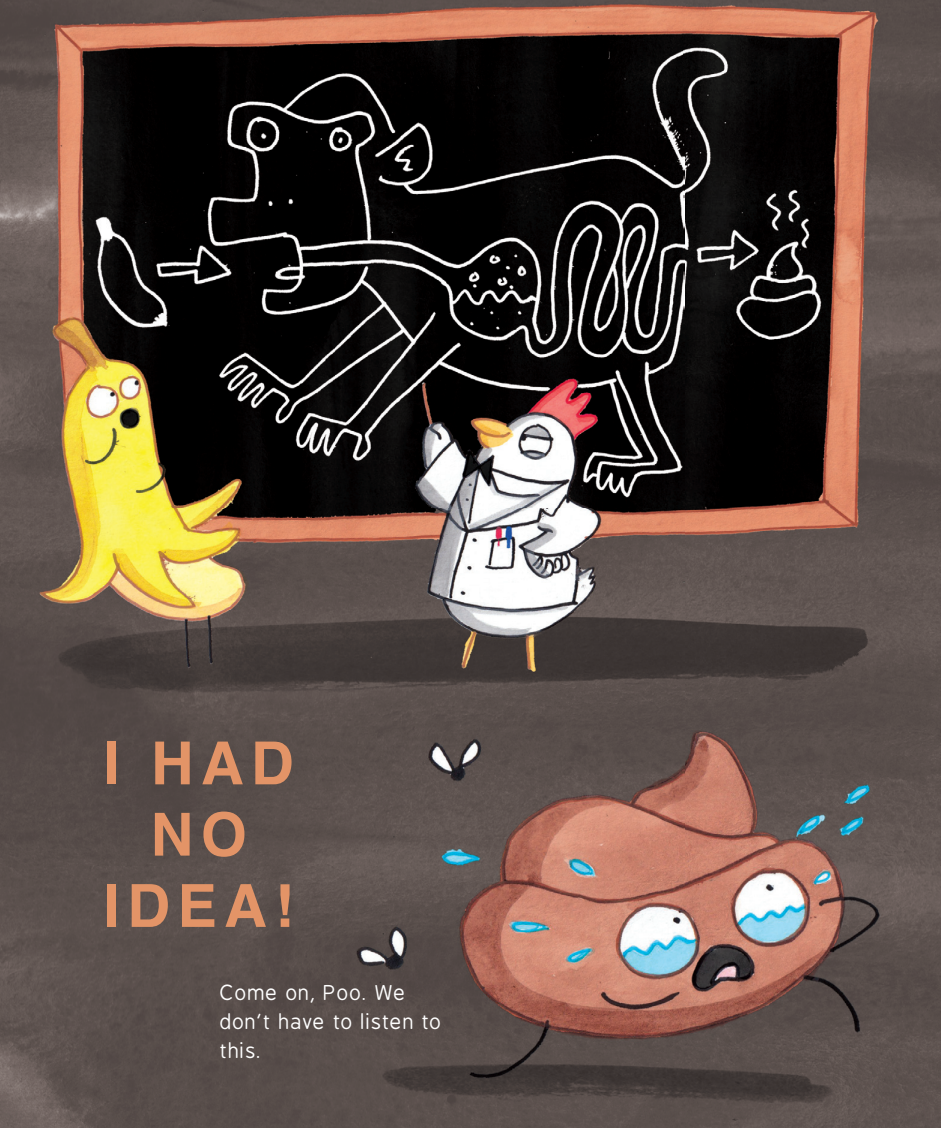

\section{BRIAN!}

Oh no, it can't be. I thought he was on annual leave. It's... it's...

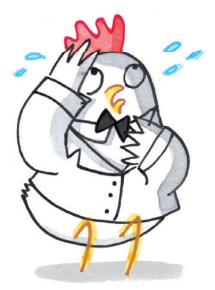




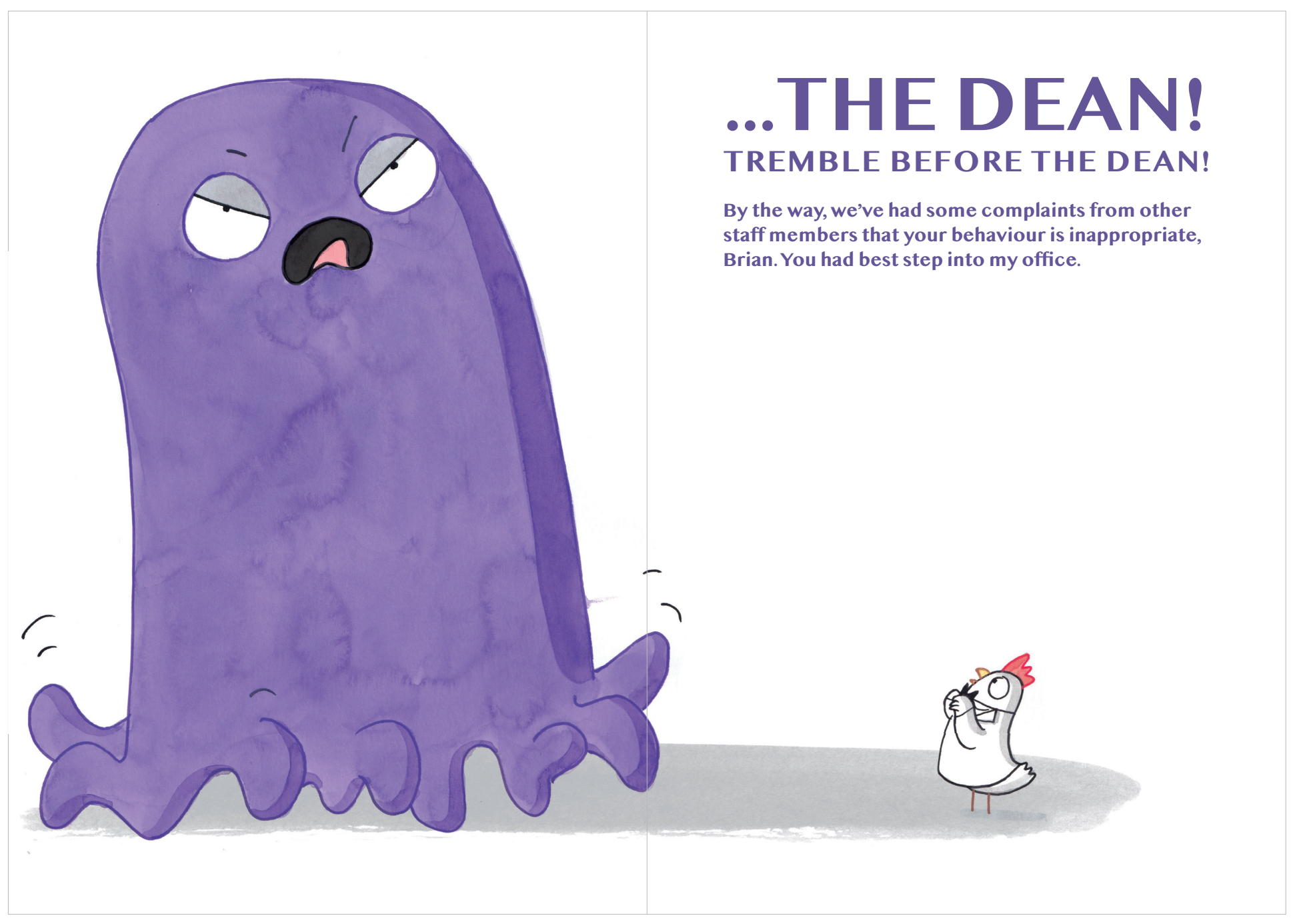




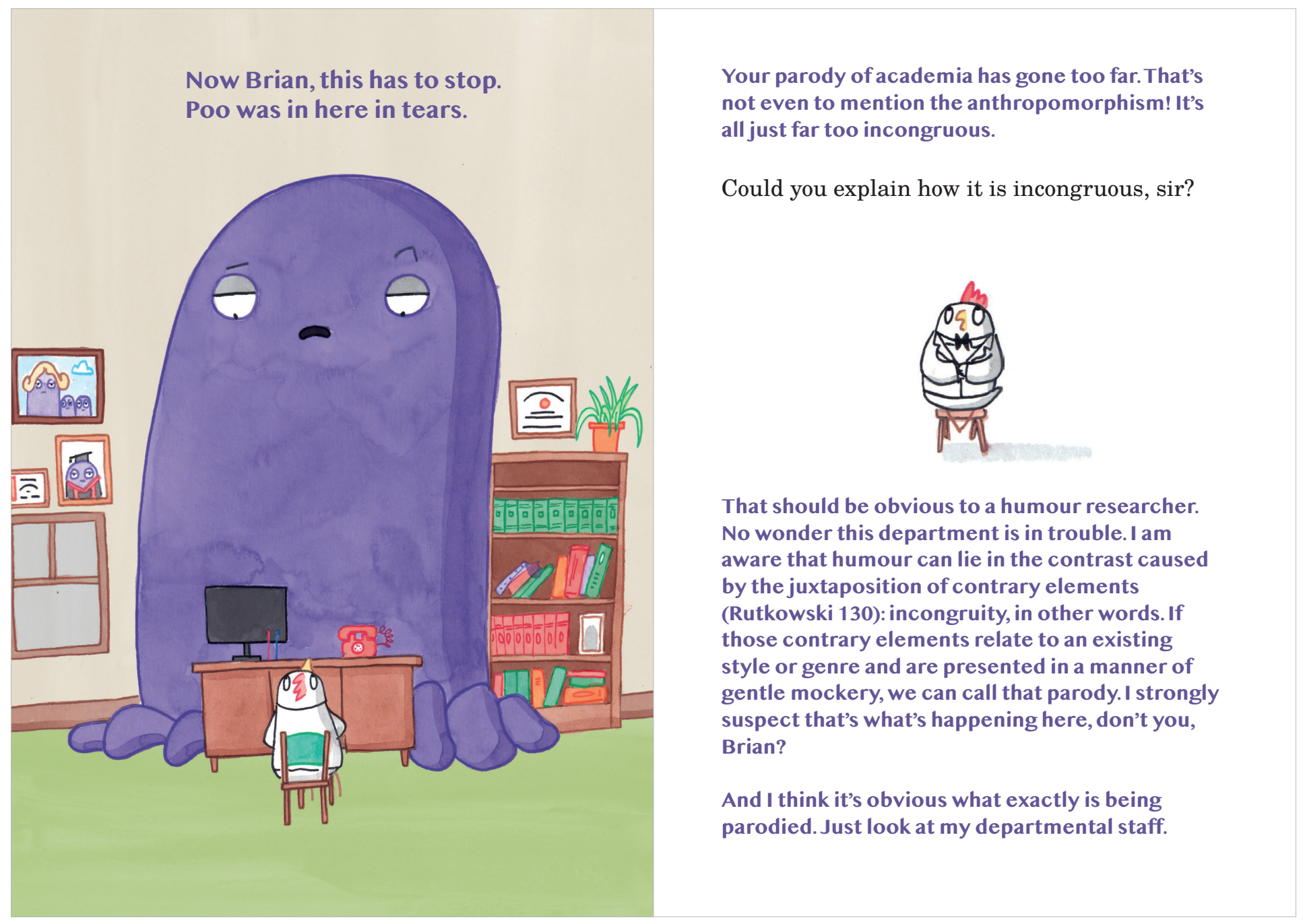




\section{Incongruity}

Through anthropomorphization.
Custodian

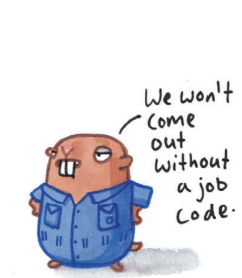

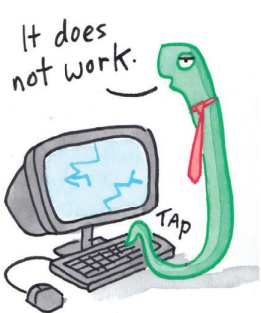

I.T.

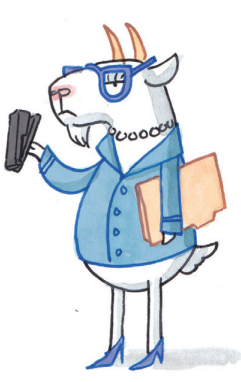

Admin

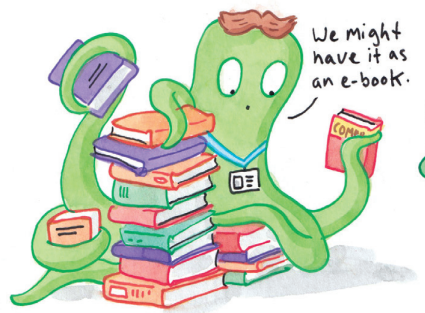

Subject Librarian

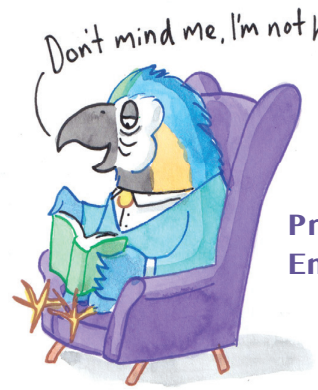

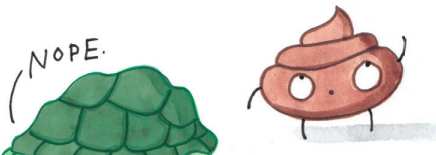

Lecturer

\section{Department}

Chair

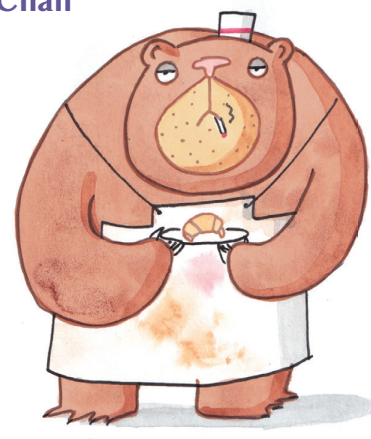

Catering
They're blatantly anthropomorphized, Brian.

Now, this could be seen as humorous in itself. The combination of non-human characters in human situations is incongruous. But in this case, the humorous effect is taken a step further. It's clear that some of the conventions of academia are being combined with anthropomorphism, arguably a common feature of children's books, and both are presented in a ridiculous light. It's obviously mocking both academia and children's books. This entire situation is a parody, Brian, if not a satire!

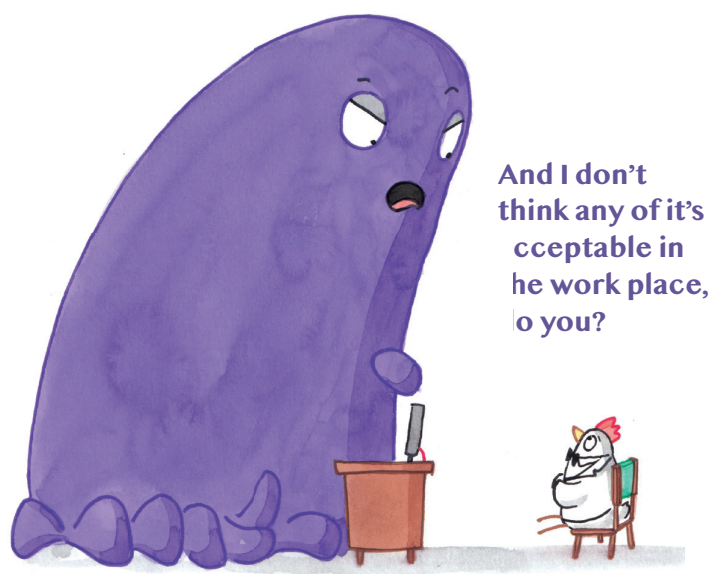

I mean, for goodness sake Brian, you're a chicken in a bow tie and I'm a huge purple blob! You realize I'll have to inform HR. Now finish your lecture. 


\section{The Rule of Throm}

Where was I? Ah. Lesley B suggests that there's some about the rhythm of threes lends itself to comedy. Thr create a pattern of "set-up establishment and punchli (5). In picturebooks, we of 1 see that the punchline tak form of a disruption, or be violation, of that pattern.

Observe Underpants Monl

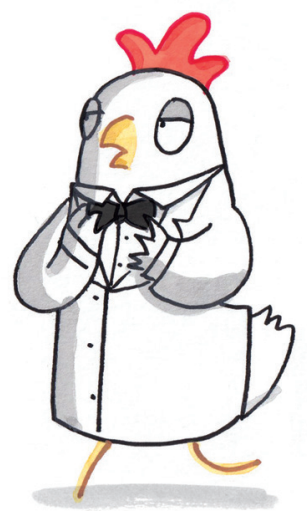

\section{Monkey likes:}

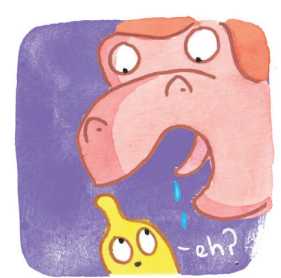

Banana.

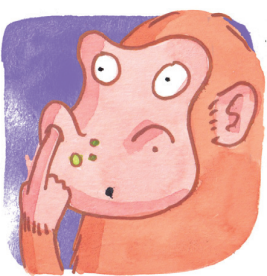

Nose.

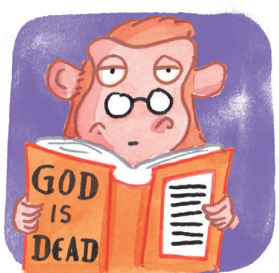

Nietzsche.
Note how he purports to like lowbrow things, but then that pattern is benignly violated by an incongruous contrast, his love of Nietzche (about which I believe he is lying).
There are ways in which pacing can be utilized to deliver this disruption of a pattern with more impact. Allow me to demonstrate. Take the way I approach my job as an academic:

\section{I do it with panache!}

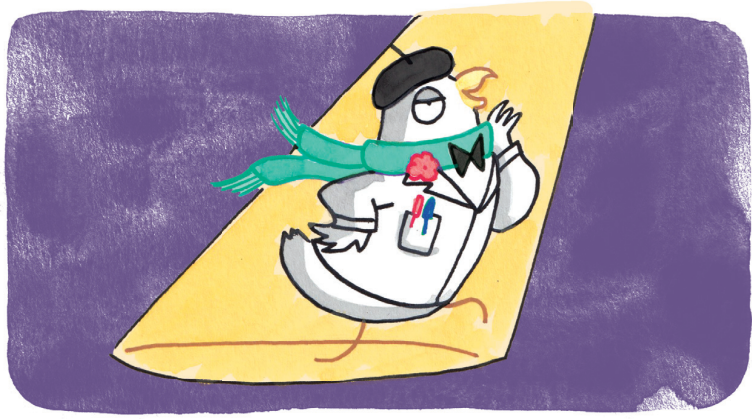

With vigour!

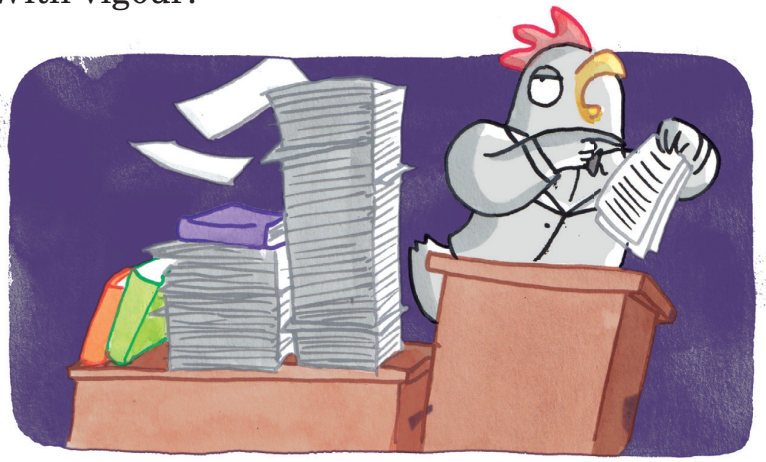




\section{with BOW TIES!}

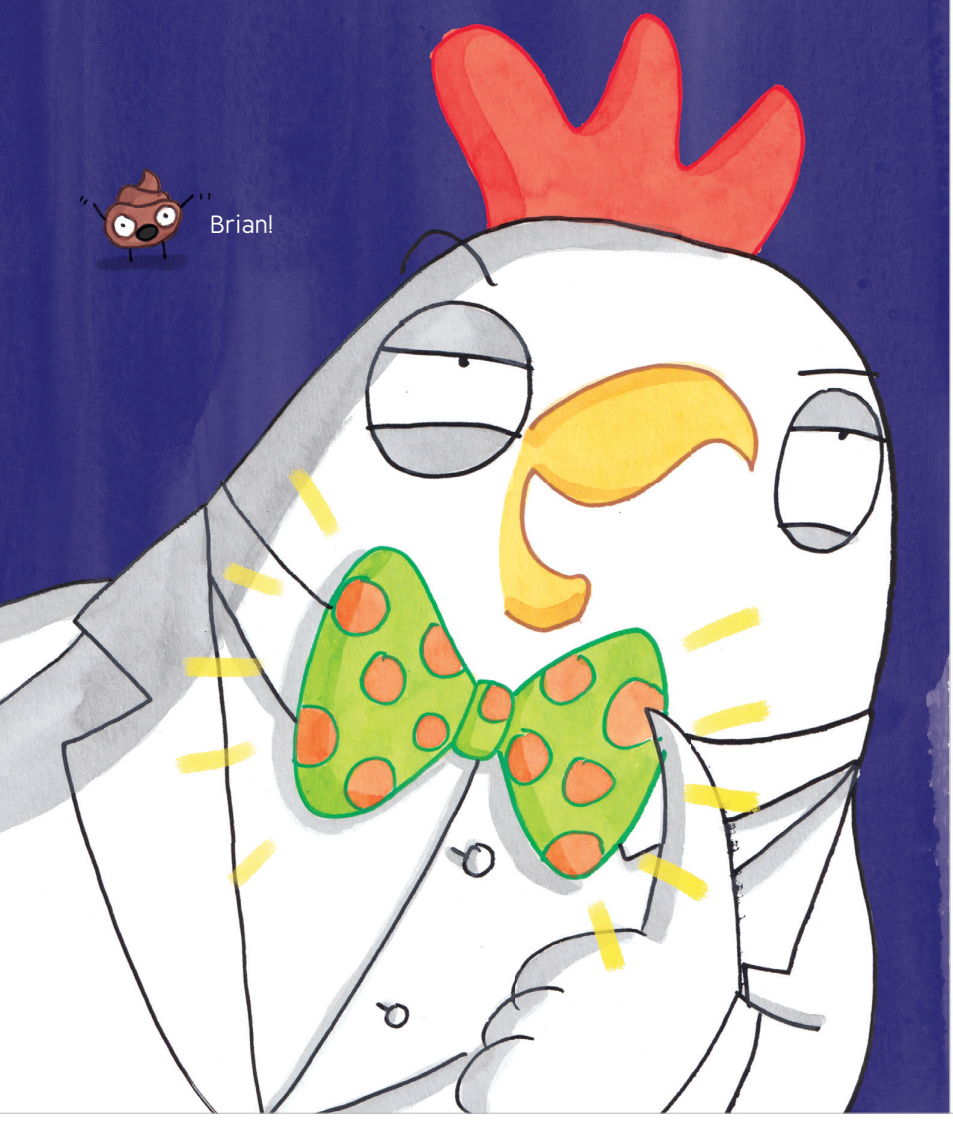

\section{Timing}

Note the page turn and scale change between the set-up and the violation. This is to create a change in the pacing.

Martin Salisbury defines pacing as the rate at which the story unfolds and can be controlled by "changing the viewpoint, varying the size of images and altering the actual design of the image on the page" (82). This is because, as Scott McCloud (100) states, we perceive time spatially when reading a visual narrative. It is by manipulating the amount of physical space dedicated to a particular moment, along with the space between such moments, that we can create the illusion of time passing.

The page turn is significant in that it creates a pause in the sequence. We can utilize that pause to create suspense. In addition, the page turn conceals the punchline, creating the effect of surprise when the page is turned and the punchline revealed.

What I did here was use these tools of pacing for the purpose of creating favourable comic timing. The larger scale implies significance and invites the reader to linger on that moment. The pause and reveal of the page turn is equally important. This is because we can intensify a comic effect by placing emphasis on the pause before the payoff. The tension before the reveal of the punchline is often the key to a joke, so timing its build-up and eventual reveal is crucial. This is a more dramatic way of delivering a "rule of three" violation than shown in "Monkey Likes." 
On the subject of reveals, adding new and surprising information in a scene can create a humorous effect. Allow me to demonstrate:
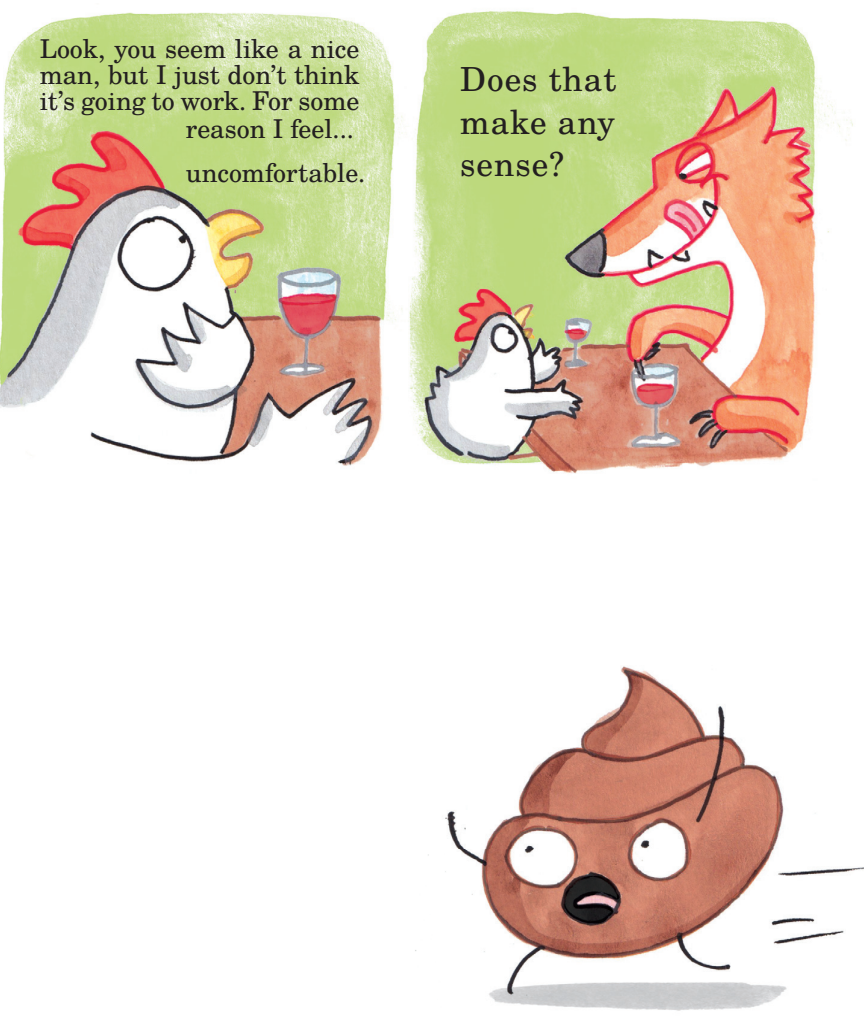

The Vice Chancellor is coming!
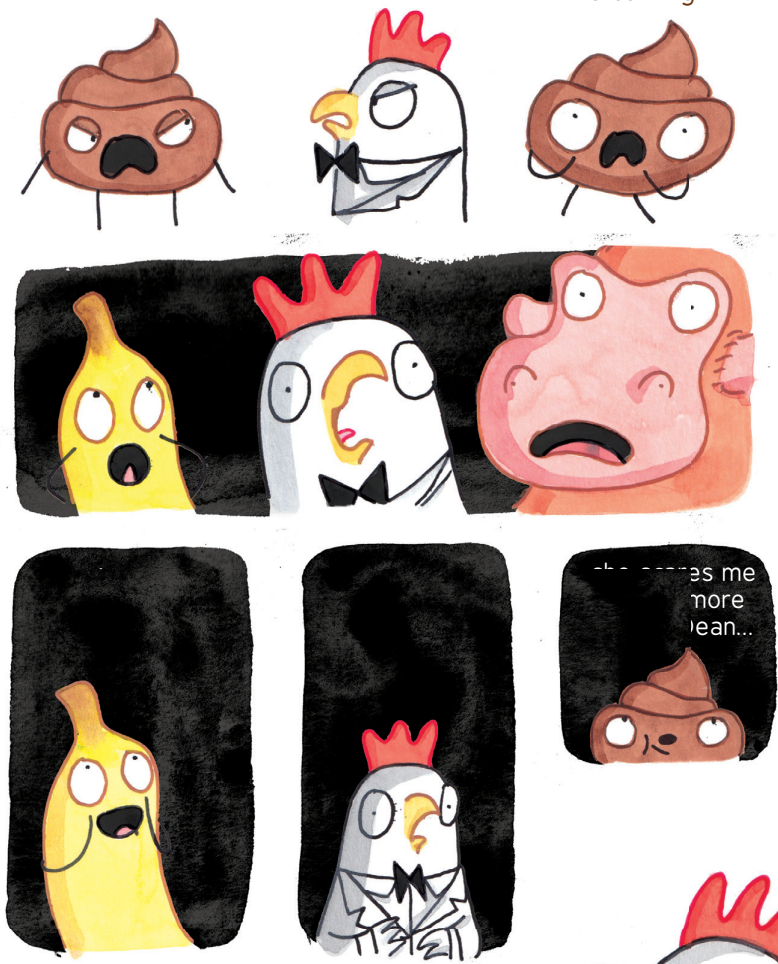

...she's ...here.

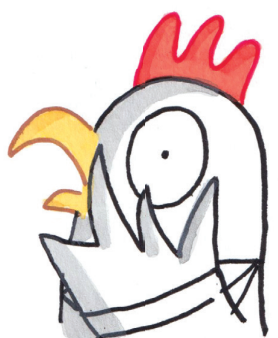




\section{Gentlemen.}

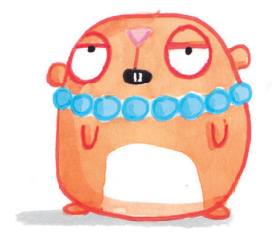



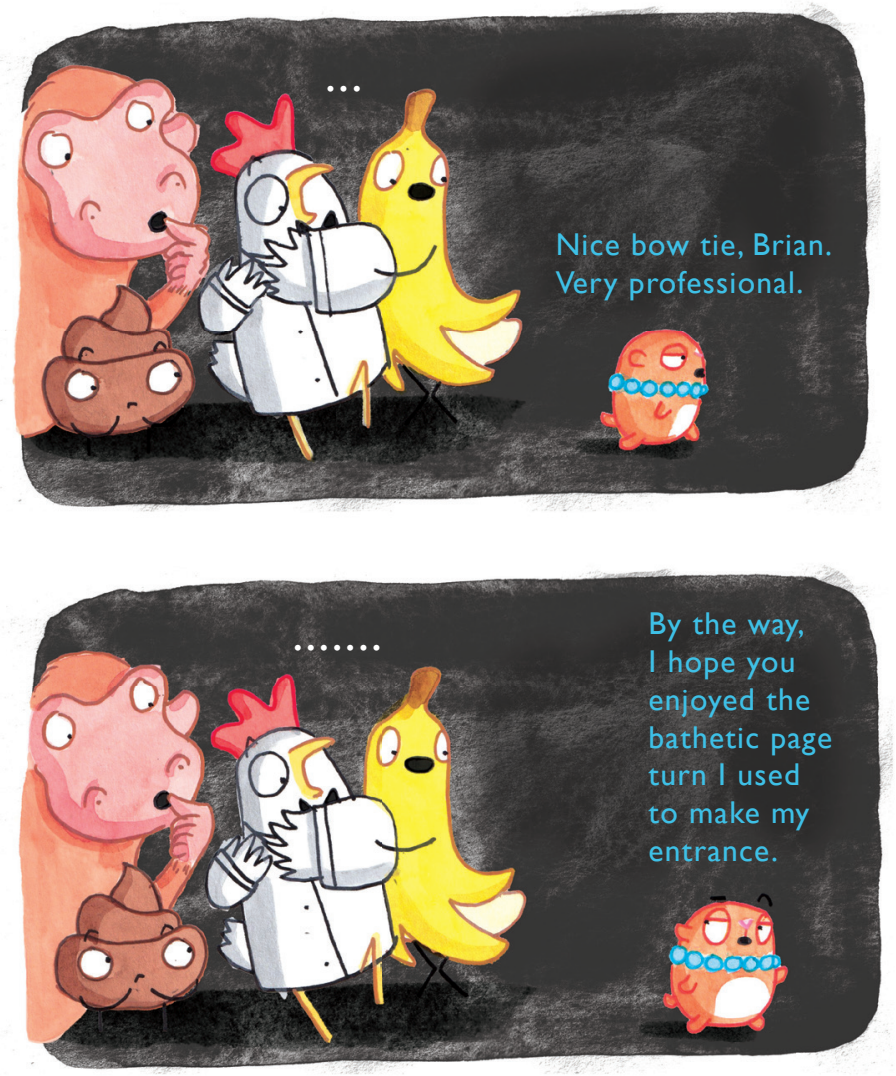

I heard you talking about pacing and page turns to deliver a joke and I thought, I could add a little something extra, a bit of bathos.

We could say that bathos is going from "the sublime to the ridiculous" (Brown 5), the "ludicrous descent from the elevated to the commonplace" (Crangle and Nicholls 9). It can be seen in picturebooks when something is set up as being important, serious, or highbrow and then revealed to be the opposite.

I did the same here because your twittering about my terrifying nature set me up as an imposing figure, perhaps a monstrous entity like the Dean, but the page turn revealed me to be an adorable little hamster, which I'm told can be a tad unexpected.

Comedian Richard Herring suggests that often jokes are based on the surprise caused when there's a twist to our perceived logic. I dare say that's what I was doing here. My appearance twisted what the audience had logically come to expect. I "benignly violated" it, as you would say.

I thought you'd appreciate that, Brian, as this is your specialism. Apparently. 

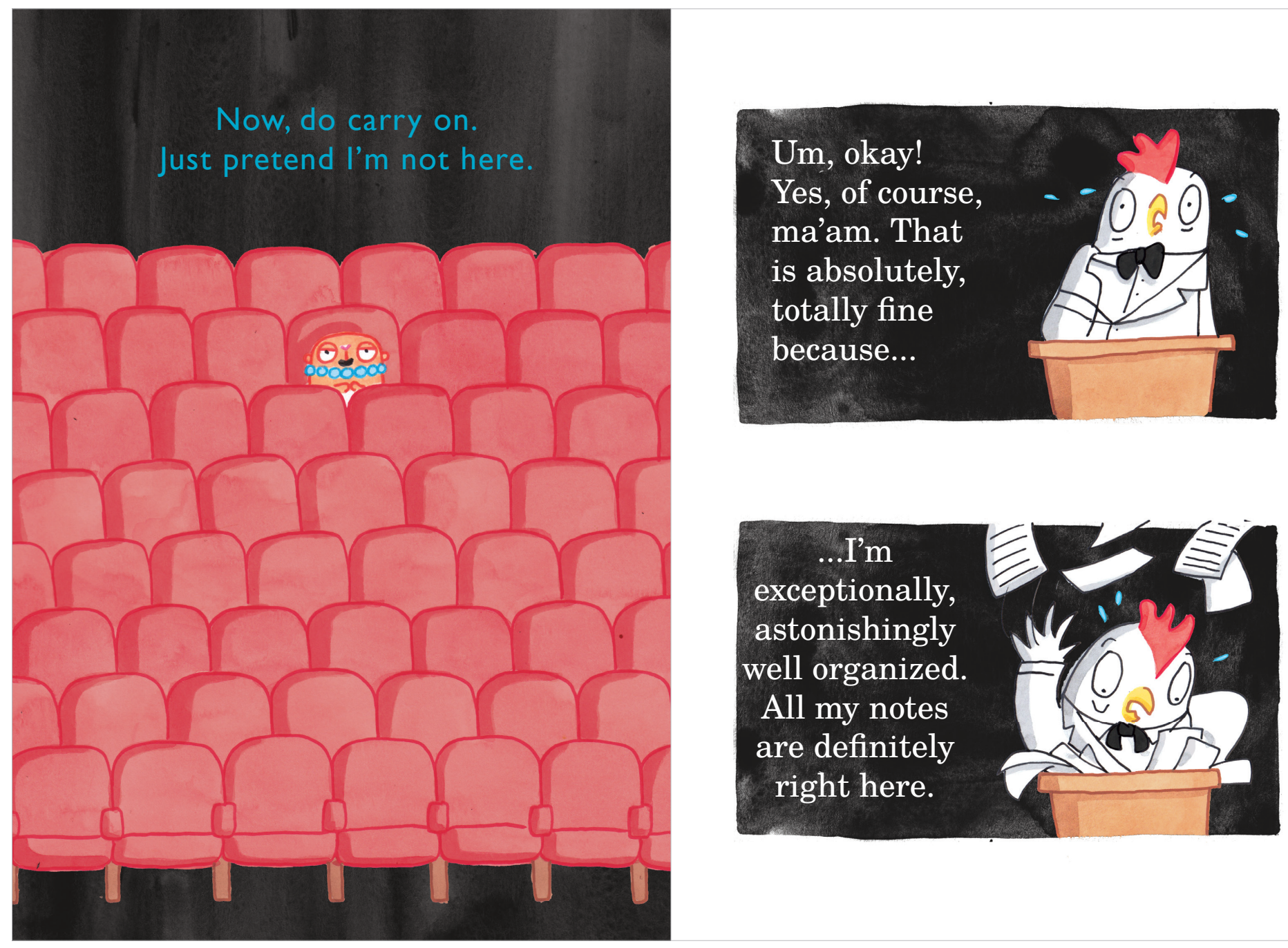
In fact, my research is so clear it speaks for itself.

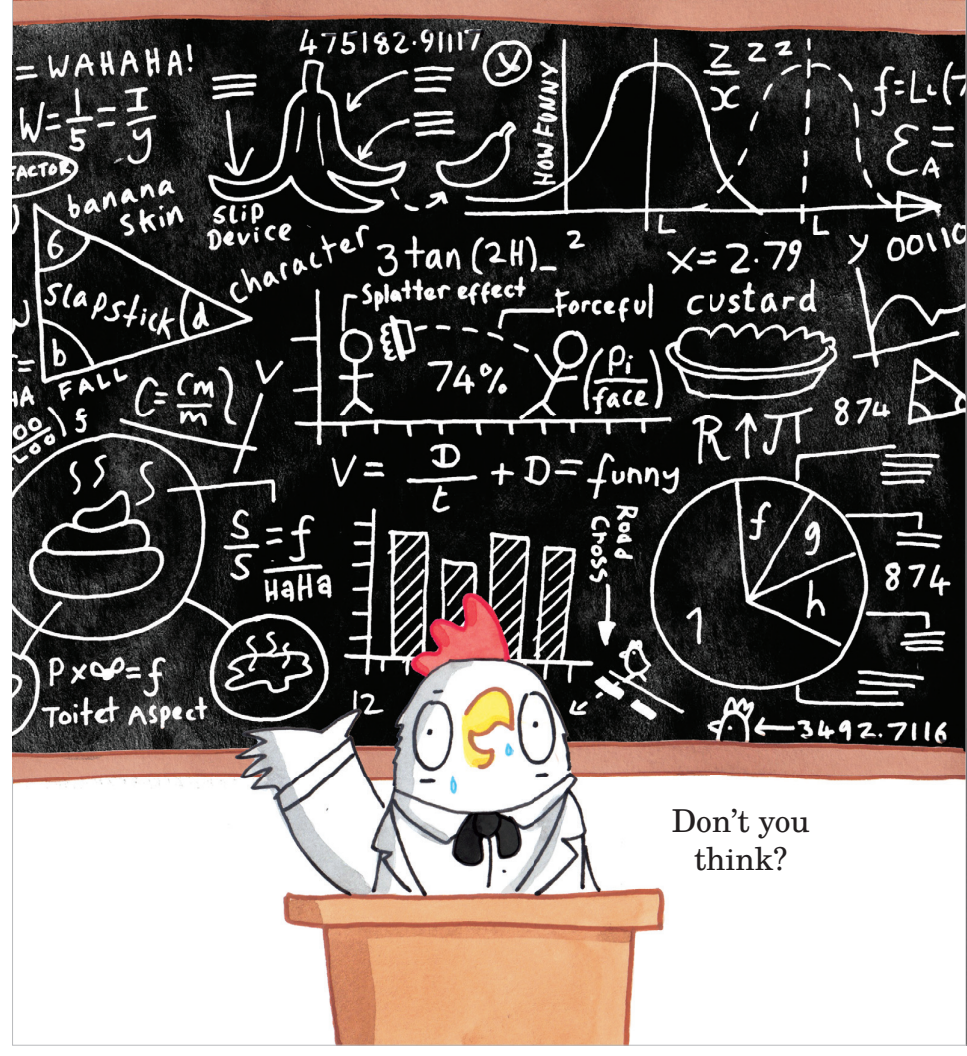

And my delivery is sophisticated yet entertaining.

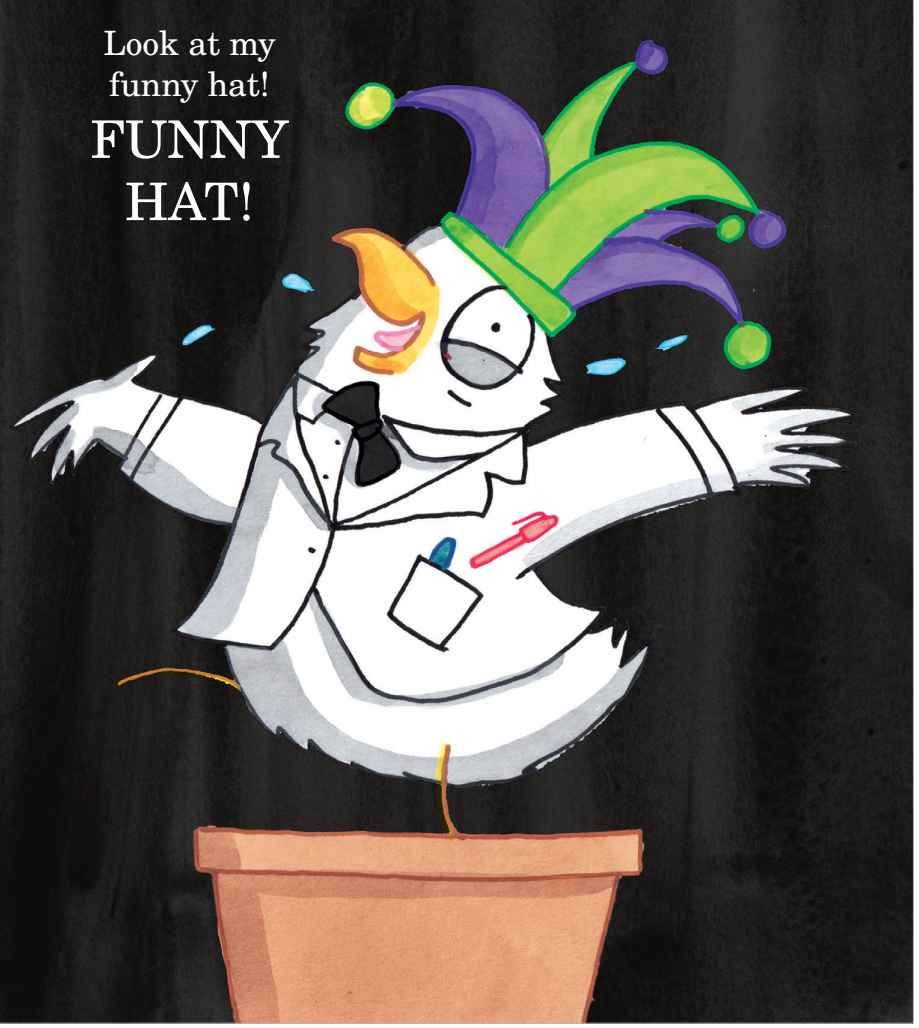




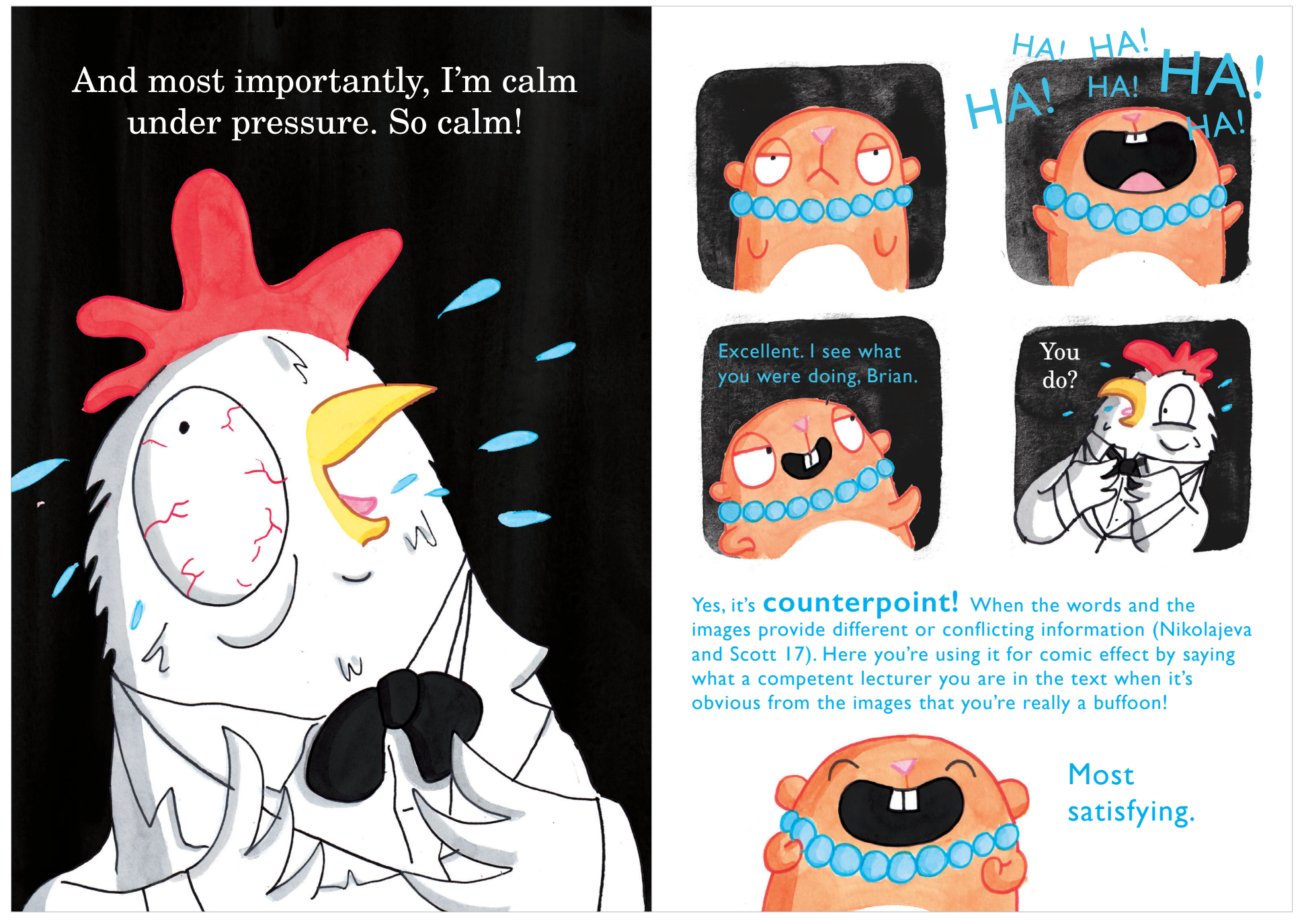


Very good, Brian, you make the relationship between word and image so ironic, incongruous even! It benignly violates the expectations you set up through the words. It also really appeals to my excellent sense of humour. exactly what I was doing. Of course. Obviously.

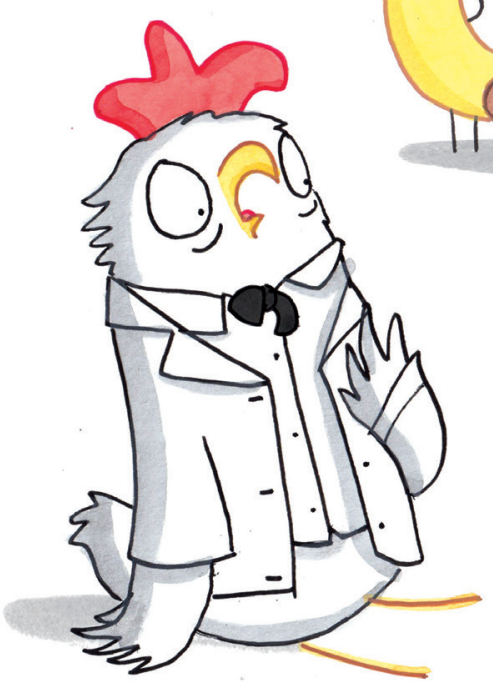

Now why don't you wrap up your lecture. Someone has this lecture theatre booked afterwards, you know.

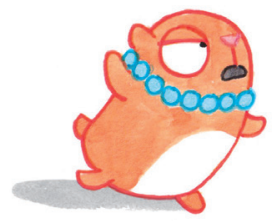

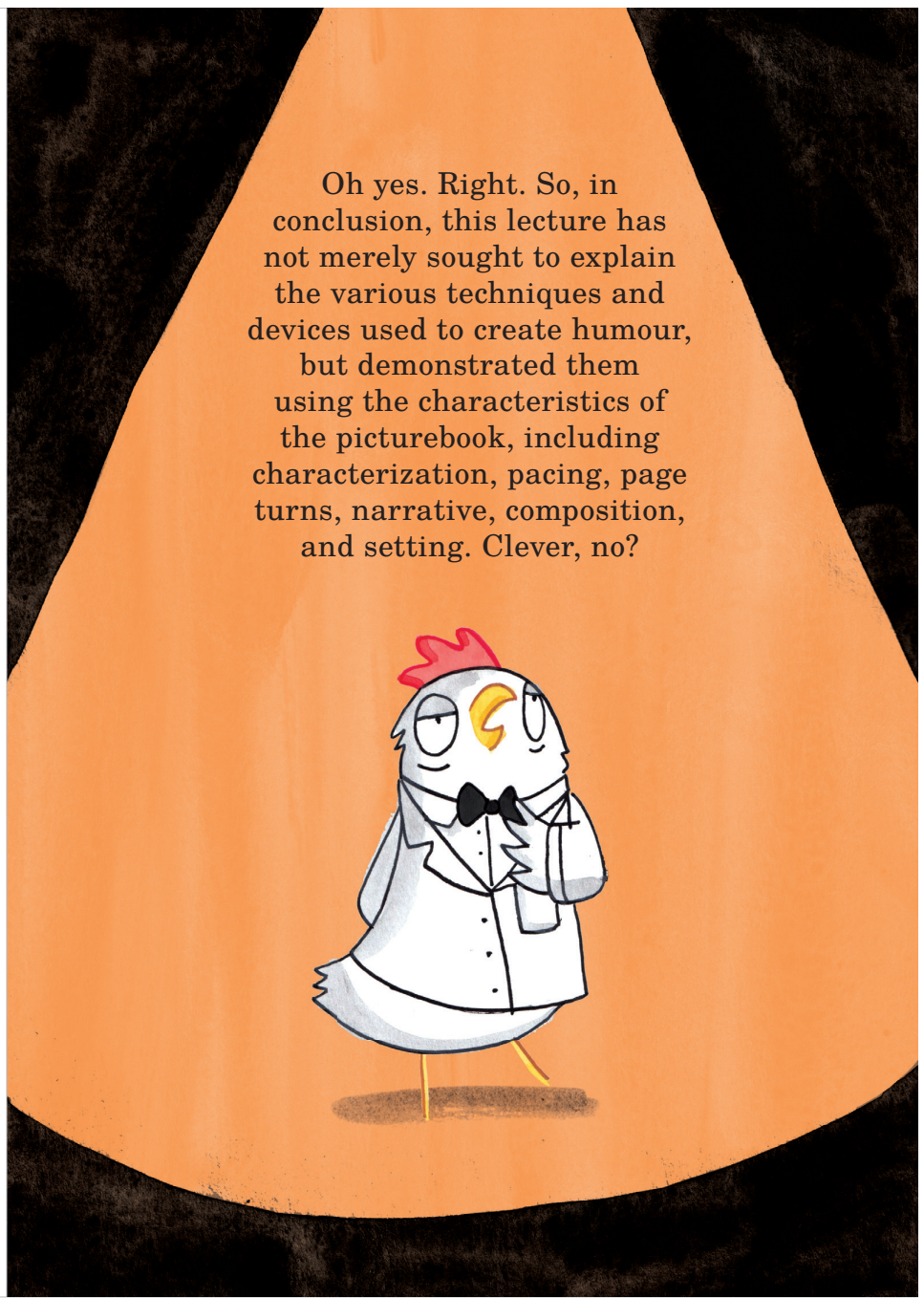

Elys Dolan 
I believe to actively witness types of humour and comic devices in context...

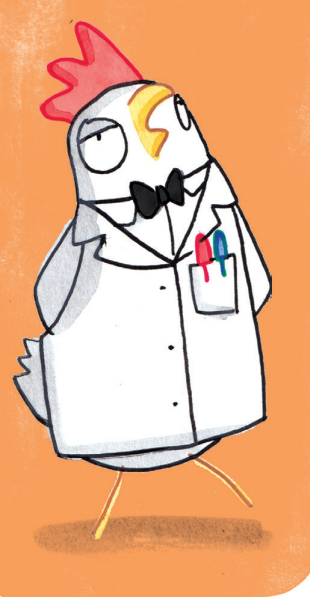

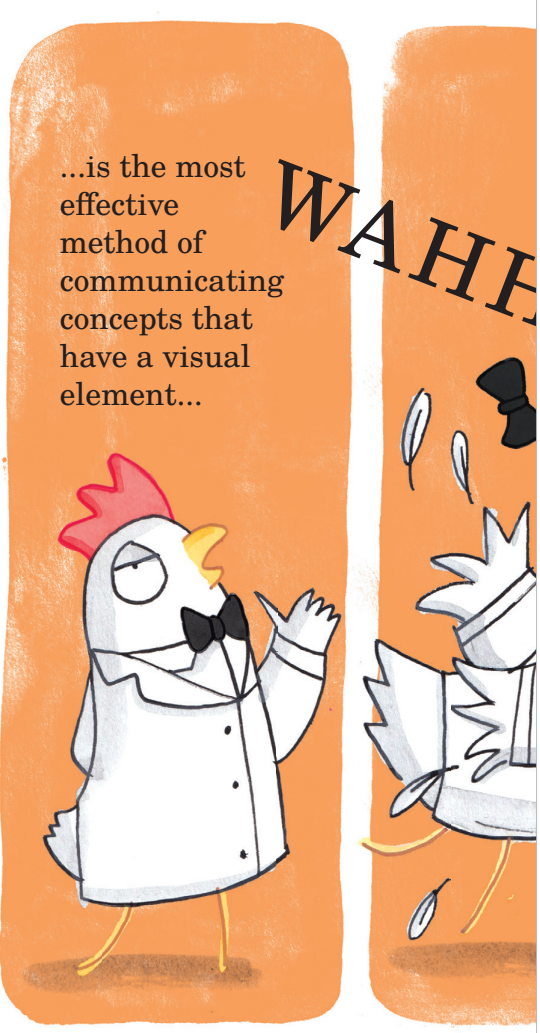

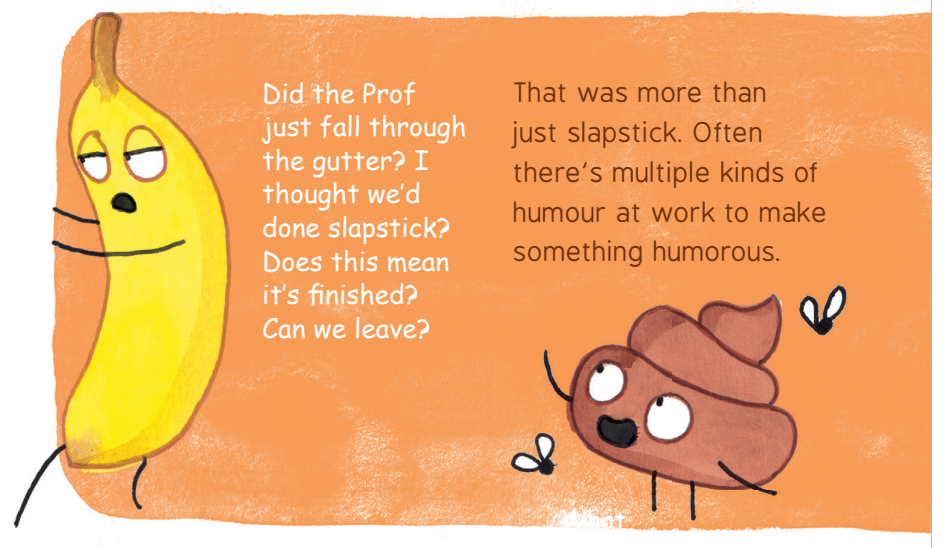

Take Underpants Monkey... PAN NTS

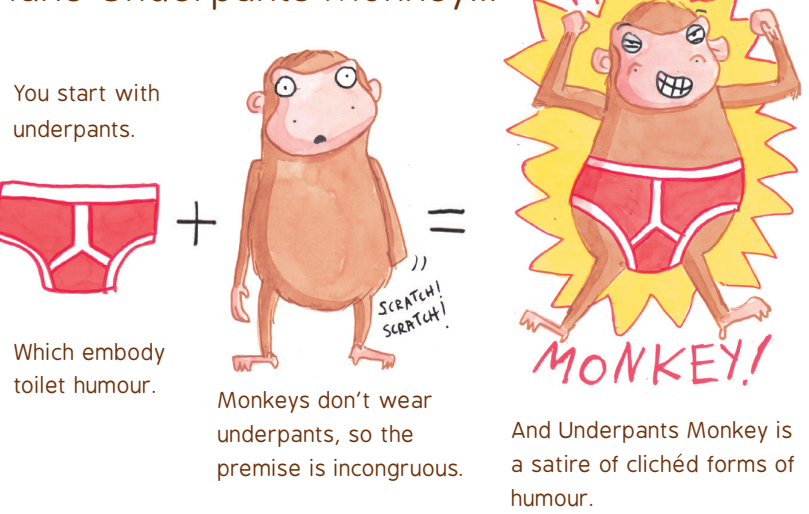

So, you can see there's three types of humour at work here. 
The Professor used slapstick, but he also benignly violated the conventions of the picturebook by falling through the gutter, an aspect of the book as an artifact that we are expected to ignore, so creating an incongruous situation.
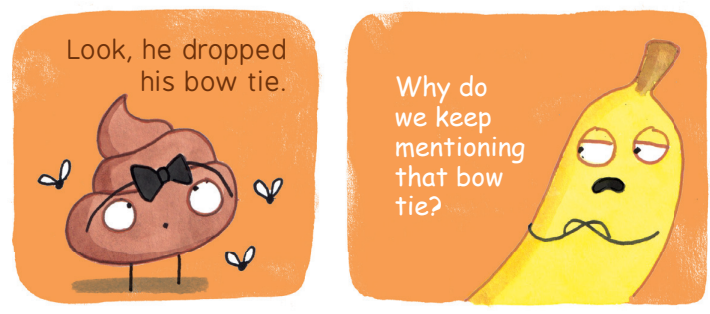

I imagine it's a running joke or a subplot that the Professor has been setting up throughout this entire lecture. Repetition and familiarity can be versatile humorous devices. It could be said that these sorts of subplots are rather like a "call back," another humorous device. This is when a reference is made to a previous joke but often in a different context.
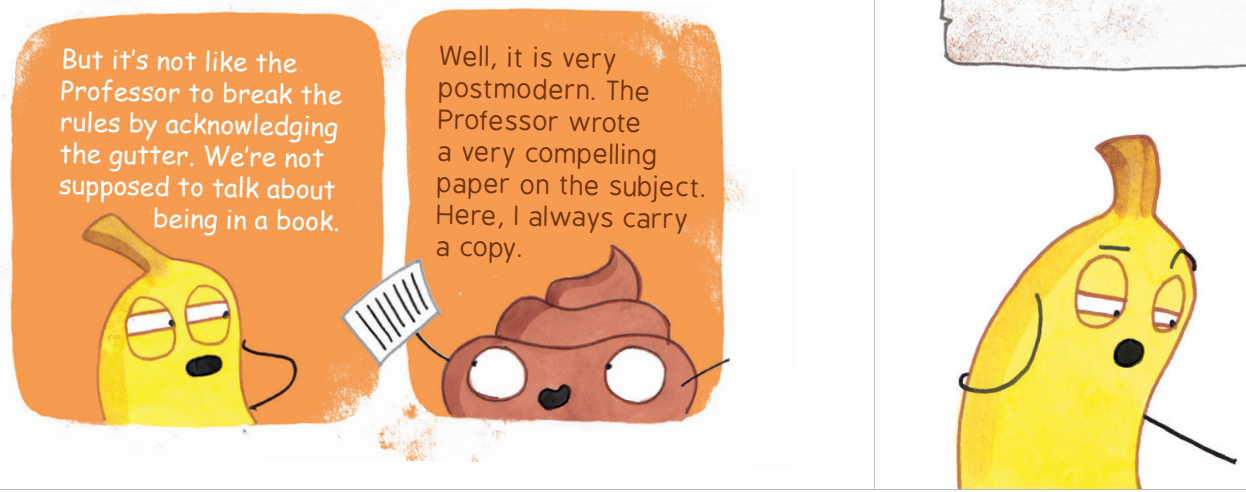

That's very wordy... hang on, can you hear something coming from down there? 


\section{Works Cited}

Bader, Barbara. American Picturebooks from Noah's Ark to the Beast Within. Macmillan, 1976.

Brown, Lesley. Writing Comedy. Hachette, 2015.

Crangle, Sara, and Peter Nicholls. On Bathos: Literature, Art, Music. Bloomsbury, 2010.

Herring, Richard. "How to Write a Joke." The Guardian, 22 Sep. 2008 , theguardian.com/books/2008/sep/22/comedy.

Levin, Harry. Playboys and Killjoys: An Essay on the Theory and Practice of Comedy. Oxford UP, 1987.

McCloud, Scott. Understanding Comics: The Invisible Art.

HarperPerennial, 1994

McGraw, Peter, and Joel Warner. The Humor Code: A Global Search for What Makes Things Funny. Simon and Schuster, 2014

Monro, David. "Theories of Humor." Writing and Reading Across the Curriculum. 3rd ed., edited by Laurence Behrens and Leonard J. Rosen, Scott, 1988, pp. 349-55.

Nikolajeva, Maria, and Carole Scott. How Picturebooks Work. Routledge, 2001.

Nikolajeva, Maria. The Rhetoric of Character in Children's Literature. Scarecrow, 2003.

Pantaleo, Sylvia, and Lawrence Sipe. "Introduction: Postmodernism and Picturebooks." Postmodern Picturebooks: Play, Parody, and SelfReferentiality, edited by Lawrence R. Sipe and Sylvia Pantaleo, Routledge, 2008, pp. 1-8.

Rutkowski, Mariusz. "Humorous Names in the Light of Incongruity Theory.” Voprosy onomastiki, vol. 13, no. 1, 2016, pp. 129-39, doi: 10.15826/vopr_onom.2016.13.1.007.

Rosen, Michael. "My Professorial Inaugural Lecture at Goldsmiths, University of London: Humour in Children's Books." Michael Rosen, 11 July 2014, michaelrosenblog.blogspot.com/2014/07/my-professorial- inaugural-lecture-at.html. Accessed 14 Feb. 2021.

Salisbury, Martin. Illustrating Children's Books: Creating Pictures for Publication. A. \& C. Black, 2004.

Saxby, Maurice. Books in the Life of a Child: Bridges to Literature and Learning. Macmillan Education Australia, 1997.

Weitz, Eric. The Cambridge Introduction to Comedy. Cambridge UP, 2009 .

White, E. B., and Katharine S. White. "The Preachin Humorist." The Saturday Review of Literature, 18 Oct. 1941 , p. 16

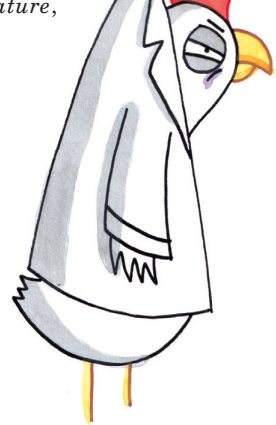




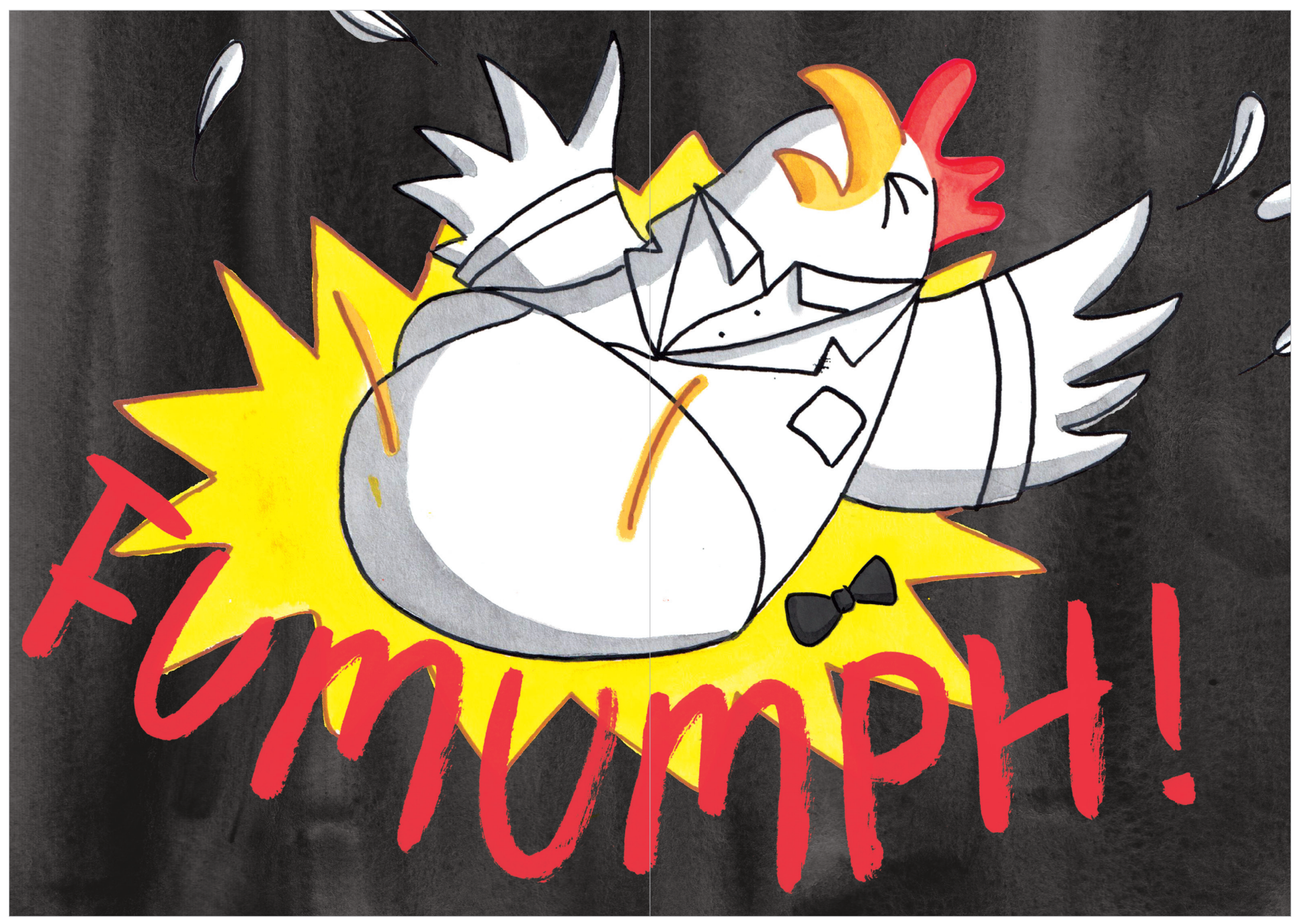




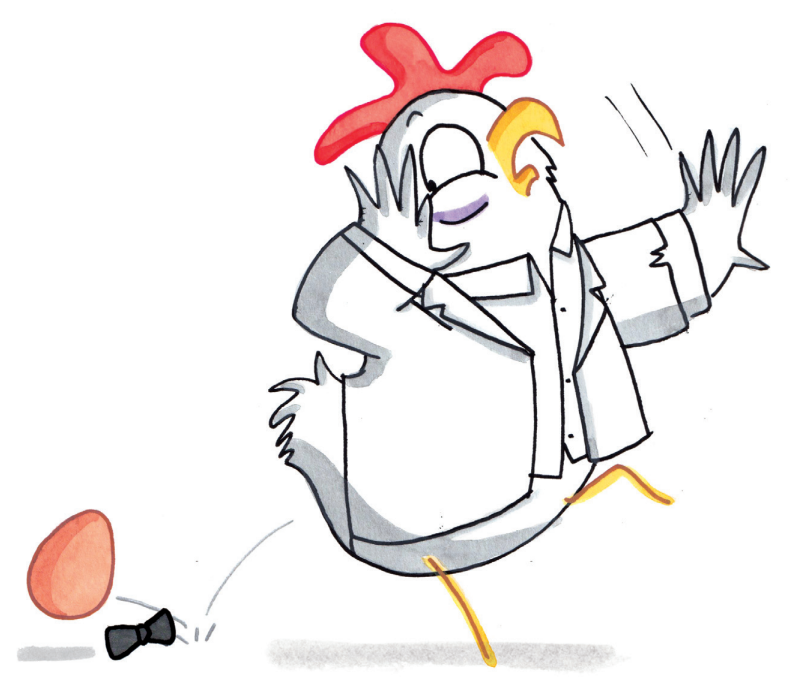

And I think this just about brings us to the end of the lecture. Thank you for listening. I won't be taking any questions.

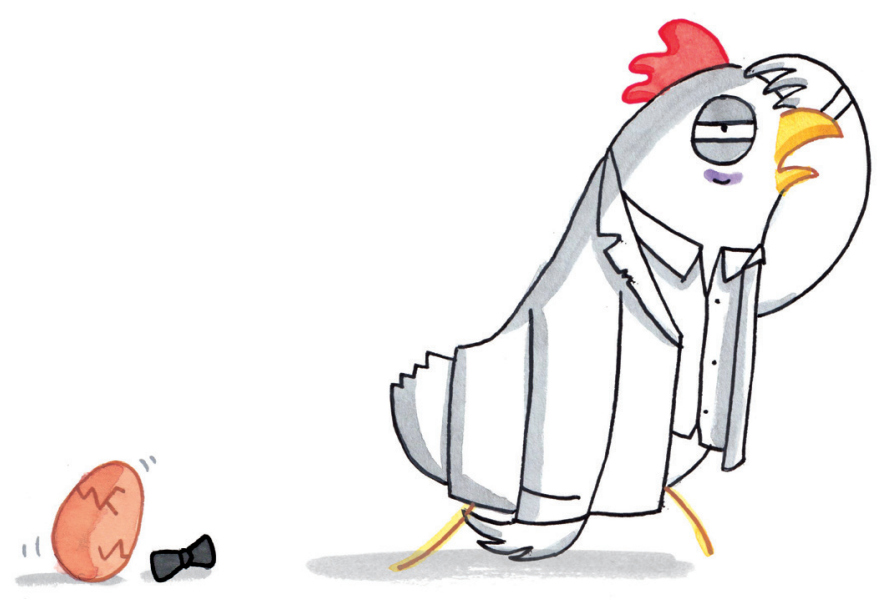

Instead, I'm taking a sabbatical. 


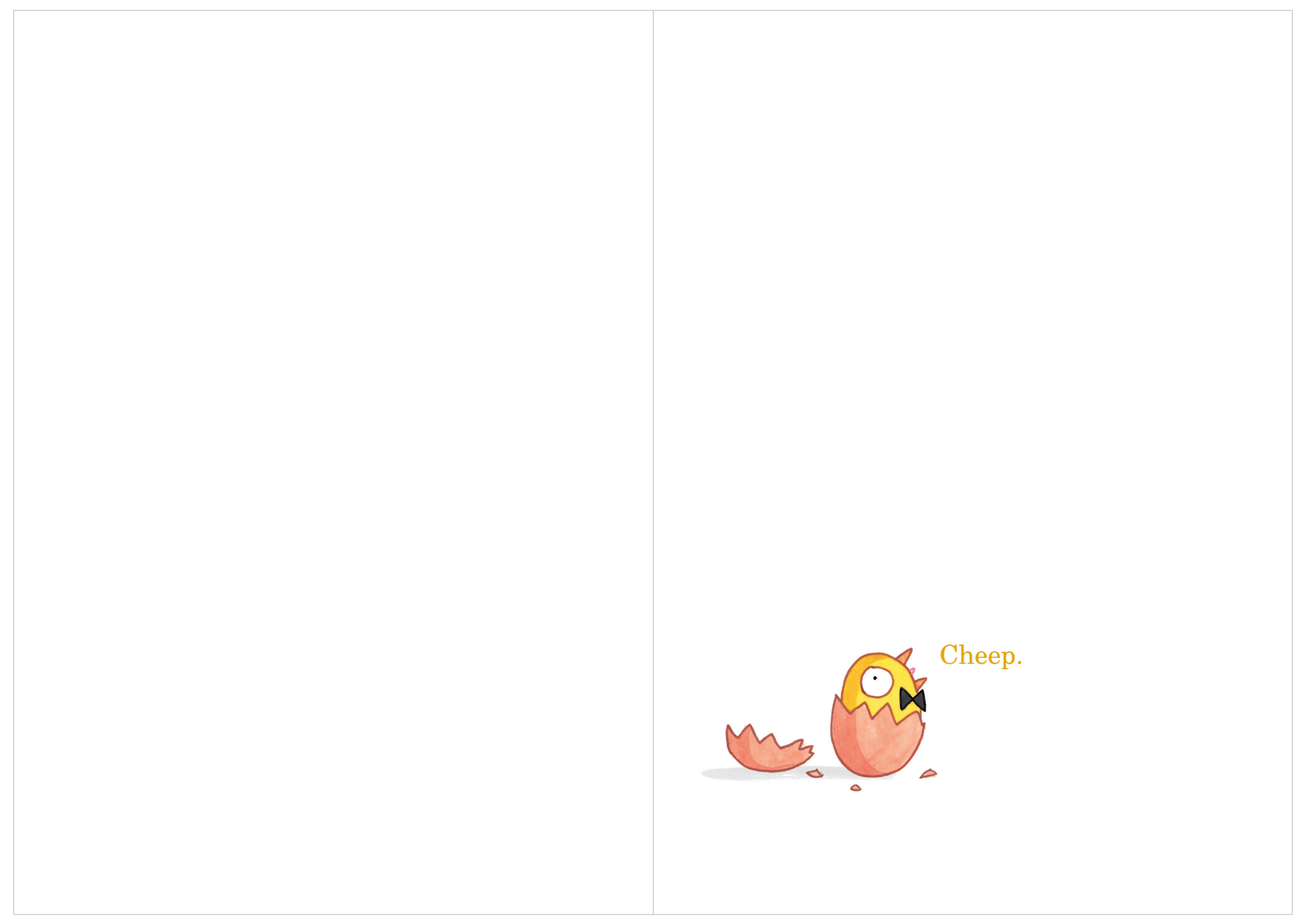


Dr. Elys Dolan lectures in the MA in Children's Book Illustration program at the Cambridge School of Art, Anglia Ruskin University, and is a member of the Centre for Children's Book Studies. Her research specialism is humour in illustrated children's books and how it emerges through creative practice. Elys has also written and illustrated twelve internationally published children's books, ranging from picture books to illustrated middle-grade fiction. 